\title{
Understanding and Tackling Poverty and Vulnerability in Mountain Livelihoods in the Hindu Kush Himalaya
}

\author{
Coordinating Lead Authors \\ Giovanna Gioli, University of Edinburgh, UK and formerly International Centre for Integrated Mountain \\ Development, ICIMOD, Nepal, e-mail: fraugioli@gmail.com (corresponding author) \\ Ganesh Thapa, Independent researcher, former IFAD, Italy, e-mail: ganeshbthapa@gmail.com \\ Fawad Khan, ISET, Pakistan, e-mail: fmkhan@gmail.com

\section{Lead Authors} \\ Purnamita Dasgupta, Institute of Economic Growth, India, e-mail: purnamita.dasgupta@gmail.com \\ Dev Nathan, Institute for Human Development, India, e-mail: nathandev@ hotmail.com \\ Netra Chhetri, Arizona State University, USA, e-mail: Netra.Chhetri@asu.edu \\ Lipy Adhikari, International Centre for Integrated Mountain Development, ICIMOD, Nepal, \\ e-mail: lipy.adhikari@icimod.org \\ Sanjay Kumar Mohanty, International Institute for Population Studies, India, e-mail: Sanjay@iips.net \\ Elisabetta Aurino, Imperial College London, UK, e-mail: e.aurino@imperial.ac.uk \\ Laura Mapstone Scott, King’s College London, UK, e-mail: Imapstone@gmail.com
}

\section{Contributing Authors}

Jean-Yves Gerlitz, University of Bremen, Germany, e-mail: jgerlitz@bigsss-bremen.de Bidhubhusan Mohapatra, Population Council, India, e-mail: bbmahapatra@gmail.com Naresh Saxena, Independent researcher, India, e-mail: naresh.saxena@gmail.com Marjorie van Strien, Independent researcher, former ICIMOD, The Netherlands, e-mail: marjorie.vanstrien@gmail.com

Amiera Sawas, Grantham Institute, Imperial College London, UK, e-mail: amierasawas@googlemail.com

\section{Review Editors}

Enamul Haque, East West University, Dhaka and Asian Center for Development, Dhaka, Bangladesh, e-mail: akehaque@ewubd.edu; akehaque@acdonline.org

Linxiu Zhang, Center for Chinese Agricultural Policy, Chinese Academy of Sciences, China, e-mail: lxzhang.ccap@igsnrr.ac.cn

\section{Corresponding Author}

Giovanna Gioli, University of Edinburgh, UK and formerly International Centre for Integrated Mountain Development, ICIMOD, Nepal, e-mail: fraugioli@gmail.com 


\section{Contents}

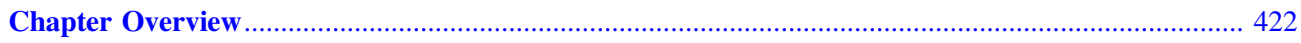

12.1 Anticipating Change: Mountain Livelihoods in a Changing Context ..................................... 425

12.1.1 Mountain Livelihoods: Trends, Challenges, and Strengths ............................................ 425

12.1.2 Livelihood Diversification in the Mountains .................................................................. 428

12.1.3 Social Protection Programmes ...................................................................................... 431

12.1.4 From Livelihood Diversification to Poverty and Vulnerability Reduction .......................... 432

12.2 Poverty in the HKH: How to Measure and Tackle It ........................................................ 432

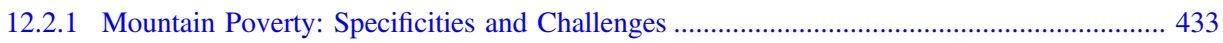

12.2.2 Economic Poverty: Levels and Trends in the HKH....................................................... 433

12.2.3 Mountains Versus Plains: Implications for Poverty …...................................................... 434

12.2.4 Poverty Rates Among Indigenous Peoples in the HKH ................................................. 436

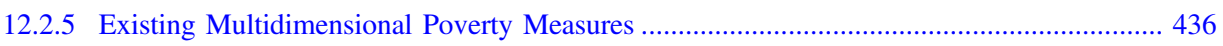

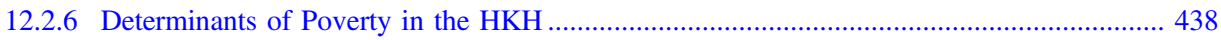

12.3 Social Vulnerability in a Changing Climate: Why It Matters in the HKH ........................... 441

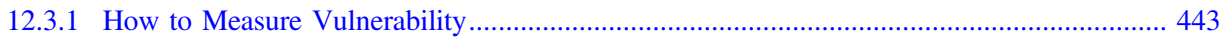

12.3.2 Linking Poverty and Vulnerability: Quantitative Vulnerability Assessments...................... 444

12.3.3 Evidence of the Intersection of Poverty and Vulnerability in the HKH ............................ 447

12.3.4 Knowledge Gaps and Recommendations .................................................................. 449

References

\section{Chapter Overview}

\section{Key Findings}

1. Overall, in the mountains and hills of the HKH region, the poverty incidence is one-third compared to one-fourth for the national average. Country-level estimates mask significant inequities between mountainous and non-mountainous regions, as well as within mountainous areas. The acute shortage of mountain-specific poverty data makes knowledge-building a high priority.

2. Poverty reduction approaches/programmes designed at national level are likely to miss crucial subnational and local manifestations of poverty. Countrywide strategies usually have limited impact on poverty reduction in the mountains and can make mountain livelihoods more vulnerable.

3. Determinants of vulnerability and of poverty in the HKH overlap substantially. Cross-countries assessments show similarities in the determinants and patterns of poverty and vulnerability in the HKH. Apart from remoteness, poor accessibility, and high dependence on natural resources, major determinants of poverty and vulnerability in the region are socioeconomic inequities, conflicts, gender inequities and caste/ethnicity-based discrimination. The $\mathrm{HKH}$ is home to millions of indigenous peoples who are economically, socially, and politically marginalized.

\section{Policy Messages}

1. Closing the income gap between the plains and mountain regions is not possible without more mountain-specific poverty-reduction programmes. Global, regional, and national institutions should allocate resources for the development of mountain specific poverty reduction policies to address three key aspects:

- Social and economic infrastructure for poverty reduction programmes has to take note of the fragile mountain ecosystem.

- Targeted approaches are required for indigenous and marginalized communities inhabiting mountains. 
- New threats from climate change require new forms of social protection.

2. The most appropriate poverty measures for mountain areas are multidimensional, addressing multiple deprivations in education, health, and living standards. Emphasis must be laid on regular/systematic collection, collation, and sharing of data among countries in the region on the determinants of poverty, duration of poverty spells, and the causes of transient poverty. The data has to be location-specific and lend themselves to disaggregation by mountain specificities, such as fragility, marginality, and remoteness. Availability of such data can help in designing poverty reduction policies and programmes that are appropriate for mountain areas. Greater investment in generating mountain-specific data is therefore called for.

3. The international benchmark for poverty in mountain areas needs to be higher than the globally accepted standard of USD 1.90 per capita per day. Mountain people experience higher costs of living due to factors such as heating costs, food prices, and access to public services. Countries must undertake cost of living surveys targeting mountain areas.

This chapter critically reviews the existing knowledge on livelihoods, poverty, and vulnerability in the Hindu Kush Himalaya $(\mathrm{HKH})$. Development in mountain areas and the practices of people in these areas are uniquely conditioned by distinct characteristics that we term "mountain specificities". Some of these specificities - such as inaccessibility, fragility, and marginality - constrain development. Otherssuch as abundant biological diversity, ecological niches, and adaptation mechanisms - present development opportunities for mountain people.

Because of these specificities, it is important to ensure that variables and indicators used in estimating poverty capture mountain specificities. For the overall HKH areas, the poverty incidence is one-third compared to one-fourth for the national averages (established but incomplete).

This chapter explores the changing contexts of HKH mountain economies and livelihoods, detailing their specific conditions and challenges. How do these specificities affect policies to measure poverty, to reduce it, and to address mountain peoples' vulnerability to climate change? Our analysis leads to policy recommendations for the region.

\section{Estimating mountain poverty using available data}

Precise measurement of mountain poverty and vulnerability is a challenge, given the large gaps in mountain-specific data for most HKH countries. National estimates can mask significant inequalities between mountain and non-mountain areas-and even between different mountain areas. The United Nations Development Programme's Multidimensional Poverty Index (MPI), as currently measured, does not take account of mountain specificities. Despite the lack of mountain-specific data on income poverty and multidimensional poverty, we have subjected the available data to as detailed an analysis as possible, resulting in the following findings:

- For income poverty, the national average of incidences vary widely among HKH countries - yet income poverty has declined in all countries over time, most rapidly in Pakistan, India, and Bhutan (well-established). National scale poverty estimates may, however, mask significant inequalities between mountain and non-mountain regions, as well as inequalities among mountain areas [established but incomplete]. For example, in Nepal, the poverty incidence in 2010/2011 was $42 \%$ in the mountains, compared with $23 \%$ in the plains and $25 \%$ nationally (well-established).

- For multidimensional poverty, national average incidences - reflected in the MPI - vary widely, from 5\% in China to 59\% in Afghanistan. However, if China and Bhutan are excluded, the multidimensional poverty rate is well above $40 \%$ across the region. As measured by the MPI, Afghanistan's multidimensional poverty ranks highest (0.35), followed by India's (0.28). China's ranks lowest (0.02), followed by Bhutan's (0.13) (well-established).

- The average intensity of deprivation is fairly consistent across HKH countries, varying from $43 \%$ in Bhutan and China to $52 \%$ in Pakistan (well-established). While citations of national poverty rates differ between the MPI and the Human Development Index (HDI), most HKH countries score poorly on both.

The HKH region is rich in cultural heritage, sacred natural sites, and pilgrimage routes that traverse the landscape and constitute the identity of its people. The extension of the argument in the specific case of mountain people, implies an emphasis on preserving the cultural identities of these communities, their cultural bonding and community resilience, that is considered to be beyond the purview of indicators captured in standard multidimensional poverty 
indices, and yet, these are an essential component of the wellbeing of mountain people (established but incomplete). In fact, Bhutan has been estimating Gross National Happiness as an alternative measure to GDP and it has four pillars: good governance, sustainable socioeconomic development, preservation and promotion of culture, and environmental conservation. The question is whether addressing poverty and vulnerability implies the need for public policy that integrates these aspects into response options for poverty and vulnerability reduction in the mountains.

\section{Determinants of poverty and vulnerability in the $H K H$}

Mountain poverty is associated with social markers and inequality at the intersection of class, caste, ethnicity, gender, education, occupation, and employment status (wellestablished). In addition, human wellbeing in mountain areas is inextricably linked to the aforementioned mountain specificities. The determinants of poverty and its persistence in the $\mathrm{HKH}$ fall into five categories:

- Remoteness and low access to markets and basic facilities

- Access to natural resources_-and high dependence on them

- Demographic factors

- Social and cultural factors

- Marginalization (political and socioeconomic).

All five types of determinants may hinder the conversion of resources, such as income, into desirable outcomes for wellbeing (increasing food and nutrition security; raising educational achievement; improving health) (established but incomplete).

Vulnerability - a pervasive aspect of livelihoods in the $\mathrm{HKH}$ - is intrinsic to mountain specificities. Mountain systems are fragile. People depend on ecosystem services. The region is highly exposed to weather variability and climate change. Similarly, poverty and vulnerability overlap to a large extent: both are multidimensional, with common causes that manifest in similar risks and outcomes (established but incomplete).

\section{Livelihood diversification in the HKH: Causes and context}

Mountain livelihoods in the HKH are evolving. The past three decades have seen a significant shift from the agro-pastoral to a combined subsistence-labour system: mountain households no longer rely entirely on their land, though they cannot make do entirely without it. Mountain households increasingly rely on livelihoods that combine farm work with non-farm activities, such as wage labour, circular labour migration, and tourism services.
The determinants of livelihood diversification in the HKH are varied. They include population growth, land fragmentation, and fast-paced urbanization, among other demographic changes. Environmental and climatic change, both global and local, is also driving diversification - as is economic globalization based on the increased connectivity that expands access to markets (well-established).

Mountain people experience these changes in a distinctive context. In the mountains of the HKH, land is scarce, for the most part, and formal property rights either do not exist or are ill-defined. Employment is largely informal; access to social and economic services-including financial instruments - is limited and social protection is limited.

Under such conditions, livelihood diversification is expected. Yet diversification alone does not adequately buffer mountain people and enable them to cope with crisis and manage risk (well-established). To provide such a buffer, targeted interventions are required. For example, as agricultural patterns shift from traditional multi-cropping to the commercialized mono-cropping of high-value commodities, the preservation of neglected and underutilized food crops (such as millet and buckwheat) can maintain genetic variety and increase food and nutrition security by offering higher resilience to climate change (established but incomplete). Such efforts are vital, given increased climate risks and persistent malnutrition. Herein, social groups and cooperatives can play a critical role in managing and using resources.

Two calls for action: Design interventions to target poverty and vulnerability now - and gather data to improve policies in the future

Mountain poverty and vulnerability often respond to the same interventions. For example, mountain-specific policies designed for the water and energy sectors can reduce poverty and livelihood vulnerability. Similarly, mountain-specific social-protection programmes can respond to new challenges driven by global climate change (inconclusive). In some cases, the joint provision of health services, decentralized energy, financial services (credit and insurance), and weather information has reduced poverty and climate risks. Furthermore, interventions that tackle challenges facing marginalized groups-including ethnic minorities-can boost economic returns from cultural tourism, alleviating poverty among the poorest, while preserving the region's ecological and cultural diversity (established but incomplete).

The above-mentioned examples show that even with existing data, successful mountain-specific interventions can be developed. Accordingly, national, regional, and global institutions should allocate resources to develop mountain-specific policies. 
This chapter highlights the urgent need for gathering longitudinal data on poverty and vulnerability determinants, the duration of poverty spells, and the causes of transition in and out of poverty - disaggregated for mountain areas, while harmonized with national surveys and databases that enable the disaggregation of data for mountain areas. If future data gathering is to include information on key potential drivers of poverty in the HKH-such as the impacts of climate and other global drivers of change on mountain-specific livelihoods - then new investments and research on the ground will be needed.

To enable mountain-specific policies and mountaindevelopment pathways that are pro-poor and genderinclusive, we urge the priority allocation of increased resources to mountain-specific data gathering, with a focus on poverty and vulnerability.

\section{Mountain Poverty and the Sustainable Devel- opment Goals}

While Sustainable Development Goal (SDG) 1 commits nations to eradicating poverty by 2030 , the mountain specificities detailed in this chapter suggest that SDG 1 must be applied in distinct ways to mountain areas.

- First, because mountain people experience higher heating costs, higher calorie requirements, and higher food commodity prices, the international income threshold of extreme poverty for $\mathrm{HKH}$ mountain areas should exceed the globally accepted standard of USD 1.90 per capita per day.

- Second, because poverty is generally higher in the mountains of the HKH than in the plains, eradicating national poverty by 2030 will require a higher rate of poverty reduction in mountain areas.

- Third, in meeting SDG Target 1.2-"By 2030, reduce at least by half the proportion of men, women, and children of all ages living in poverty in all its dimensions according to national definitions" - the governments of the HKH should promote the use of multidimensional poverty measures. Such measures are more appropriate generally and, particularly, for the mountains.

- Fourth, poverty reduction programmes must focus more on indigenous peoples, women, and other marginalized social groups, among which the incidence of poverty is most severe. Social protection programmes are needed.

\subsection{Anticipating Change: Mountain Livelihoods in a Changing Context}

Mountain farmers have continuously adapted their farming systems to a risky and changing environment. Today, multiple transitions are affecting the mountain farming systems in the $\mathrm{HKH}$, presenting both challenges and opportunities. This section provides the context of traditional mountain livelihoods, highlighting the shifts from agro-pastoral subsistence to the multi-local livelihood diversification strategies that integrate on-farm and off-farm activities that are now prevalent in the $\mathrm{HKH}$.

\subsubsection{Mountain Livelihoods: Trends, Challenges, and Strengths}

For a majority of people in the $\mathrm{HKH}$, crop-livestock agriculture (CLA) has long been a source of livelihood (see Box 12.1). With more than 200 million smallholder farmers, agriculture constitutes $40 \%$ of the region's GDP. It also generates the bulk of livestock products-75\% of the milk and $60 \%$ of the meat - and CLA employs millions of people on farms. In CLA, the livelihood of smallholder farmers strongly depends on natural resources to support the population of humans and their livestock. Overgrazed pastures, soil erosion, forest degradation, reduced recharge of aquifers, and population growth have led to a steady decline in resource endowments (see Chap. 5). As a risk multiplier, global environmental change exacerbates these challenges, but it may also create new opportunities (see Chap. 13).

\section{Box 12.1 Mixed Crop-Livestock Agriculture}

Crop-livestock agriculture (CLA) (see Fig. 12.1) is part of a dynamic system of interactions among biophysical, social, and ecological processes that produces about half of the world's cereals and is a crucial component of food, fibre, and fuel production for developing countries (Herrero et al. 2010). CLA has long offered a sustainable way to make efficient use of available natural resources in the environmentally challenging HKH; CLA farmers rear animals mostly on grass from common-pool resources (rangeland and forest) and non food biomass from crops, while the animals supply manure and traction to agriculture. In addition to the more obvious coupling of crops and livestock, there is also the coupling of common-pool resources and household-level enterprises. 
Fig. 12.1 The dynamic system of crop-livestock agriculture in the HKH (Source developed by Netra Chhetri for this chapter)

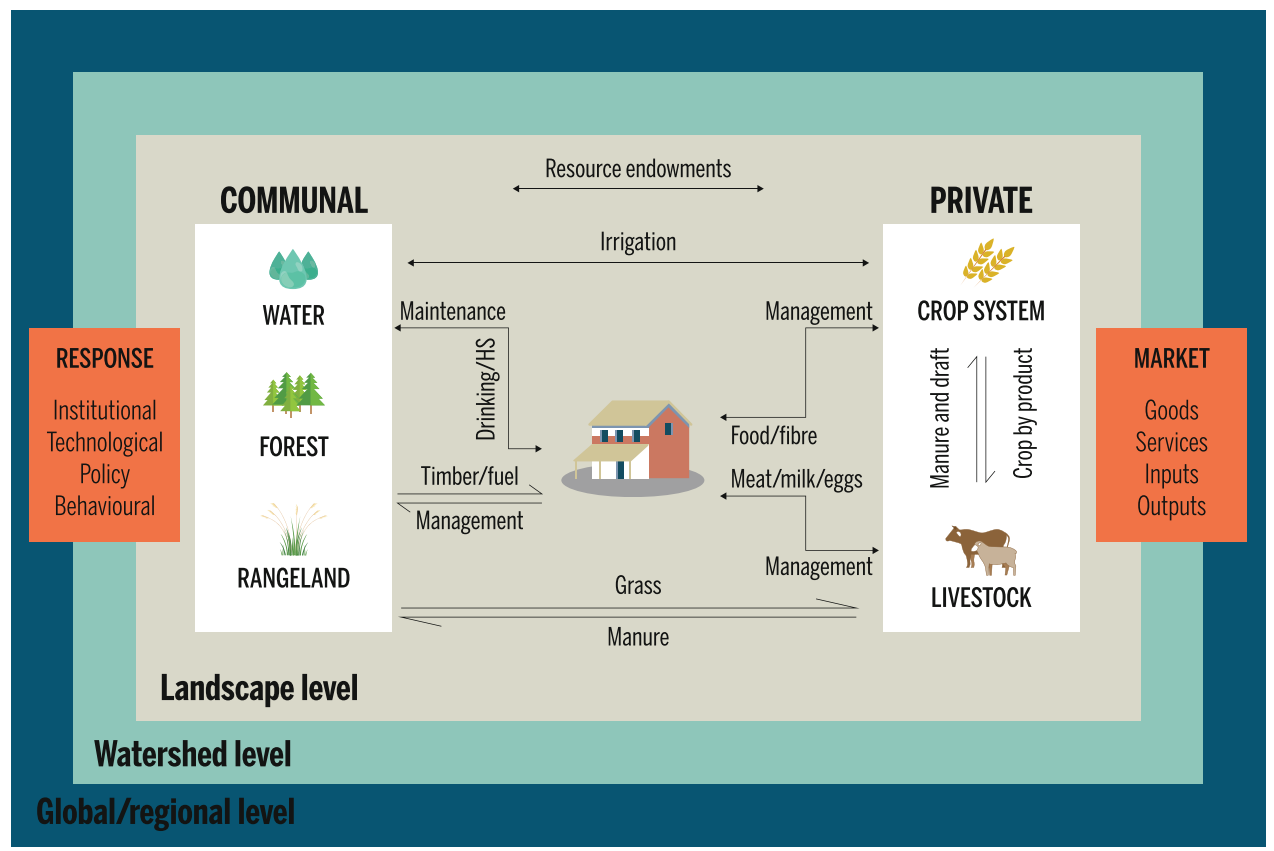

In general, livelihood conditions are strongly linked to the capacity of natural resources to support human populations and their livestock. Sustainable management of water, animal fodder, biomass, and fuelwood derived from common-pool resources is critical for ensuring the continued flow of goods and services for sustaining the livelihoods of smallholder farming communities across the HKH. Overgrazed pastures, soil erosion, forest degradation, and reduced recharge of aquifers have led to a steady decline in resource productivity. As a risk multiplier, climate change exacerbates these challenges. A well-designed research agenda focused on innovation and solutions will help sustain this unique socio-ecological system. Success will require a system-level understanding of the mixed CLA and its vulnerability to socio-ecological stimuli and shocks. To help improve current farming efficiency and the reliability of CLA, science-based and community-driven agricultural innovation and development are needed. Innovation that includes integration of scientifically based best practices with the experience and participation of a broad set of stakeholders is needed to ensure the future resiliency of the system.

By placing the household at the focus of analysis, this assessment highlights both the exogenous (risk factors) and endogenous (coping mechanisms) drivers that make the socio-ecological system of the HKH more vulnerable. Viewing the household as a primary focus of concern is not intended to undermine the importance of intra-household level data in understanding crucial gender and power dynamics, which are covered elsewhere in this assessment (see Chap. 14). Our aim is to demonstrate how the vulnerability of households is enmeshed in a complex of interlinked social, environmental, and market forces. The following sections present a review of the key emerging livelihood trends across the HKH.

\subsubsection{From Subsistence Farming to High-Value Agriculture}

The HKH has undergone a significant transformation in recent decades with respect to land use change, cropping systems, and access to markets. Farmers across the region have been gradually shifting from subsistence to high-value agriculture (Singh et al. 2011). A number of factors have been contributing to this shift, including a growing recognition of niches for high-value crops, such as fruits, vegetables, and spices like ginger, turmeric, and cardamom (Tulachan 2001; Chand et al. 2008; Adhikari 2014). The shift to high-value crops has also been facilitated by other factors, such as improved road networks providing market access for previously isolated communities, growth of remittance inflows, expansion of cooperatives, increased presence of NGOs, and targeted government activities (Kreutzmann 2006; Yi et al. 2007, 2008; Wangchuk and Siebert 2013; Khattri 2012).

Recently, high-value crops have been introduced into crop rotations, especially in the lower-elevation areas with access to markets, technology, and irrigation. In China, high-value cash crops provide farmers four times as much income as rice (Chen 2011). In Nepal, export earnings from 
the top three high-value crops (lentil, tea, and cardamom) exceed the value of cereal and dairy imports (CBS 2011). Tea, coffee, cardamom, ginger, and turmeric have evolved as important cash crops in part of the hills of Nepal (Pandey et al. 2009; Khattri 2012).

In Bhutan, traditional crops such as buckwheat, sweet potatoes, millet, wheat, naked barley, and green beans have been replaced with potatoes. Intensively cultivated potato fields are heavily fertilized with agrochemicals, and handheld traditional farming tools are substituted with small tractors (Wangchuk and Siebert 2013). A study revealed that the majority of households in the Bumthang village of Bhutan derive most of their income from the sale of potatoes, which is then used for purchasing imported rice from India (Dorji 2011). In northern Pakistan, cash crops such as potatoes and fruits (including almonds, apricots, grapes, and cherries) have been gradually introduced since the 1980s. Along with cash crops, greater connectivity (the construction of the Karakoram Highway, for example) has also greatly improved trade and income in the area (Kreutzmann 2006; Gioli et al. 2014b). A similar phenomenon has been reported in Tibet, where farmers with access to roads grow significantly more cash crops and fewer subsistence food crops, as compared to communities that are not connected to roads (Salick et al. 2005). Despite repeated crop failure, a majority of households in Ladakh, in the Indian Himalaya, continue intensive cultivation of potatoes with the hope of generating and diversifying household income, as on-farm income generation is considered vitally important (Dame and Nusser 2011).

There are several success stories associated with high-value crops. National and provincial governments in the HKH are exploring options for scaling up the successes. Two outstanding stories include vegetable and apple farming in Himachal Pradesh, India and Ningnan County, China. ${ }^{1}$ After switching from subsistence crops to high-value crops, their income and quality of life have significantly increased. The sustainability of these emerging agricultural activitiesand their competitiveness in the context of a market economy-depends upon effective management of natural resources and technological and social innovation customized to site-specific needs of smallholder farmers. The substitution of subsistence farming by high-value crops has a potential negative impact on livelihoods, as this may lead to the destruction of pasture land in the mountain areas.

While the development of high-value agriculture is crucial in addressing poverty and enhancing livelihoods options, farmers and their supporting institutions should not be complacent, as specialized agriculture is historically known to create vulnerabilities. Livelihood scholars have

\footnotetext{
${ }^{1}$ See: http://lib.icimod.org/record/22650/files/c_attachment_184_2113. pdf.
}

long viewed diversity as a central determinant of livelihood security (Chambers and Conway 1992). Traditional multiple cropping technologies, tailor-fit to a locality, could be refined and exploited to adapt against the potential threats of global environmental change and to ensure food security (Altieri 1999; Katwal n.d.). Replacing a diverse set of site-specific agricultural practices with intensive, market-driven mono-cropping (such as potatoes) tends to reduce household food self-sufficiency and increase social and ecological risk, and may reduce the wellbeing of rural households in the long run (Yi et al. 2008; Zimmerer 2010).

It is also important to note that farmers' decisions to improve their livelihoods can have negative outcomes-not only locally, through transformations of ecology and social relations, but also globally, through market channels (Adger et al. 2003). Markets in the future will be increasingly homogenized towards global requirements and demands. Food production, distribution, and marketing chains are changing along with improvements in infrastructure, communications, and vertical business structures, integration into the world market, and the rapid rise of supermarkets. New distribution channels, dominated by larger firms including supermarket retailers, will impose high performance demands on their producers and people involved in value chains. Rising energy costs will drive up the costs of fertilizers, irrigation, mechanization, and, thus, food. Systems of agriculture and their resource requirements in the $\mathrm{HKH}$ need to be efficient, not heavily reliant on external sources of fertilizer and water. As taught by the tragic 2008 melamine-in-milk episode in Asia, there is a need for strong regulation and governance to avoid inadvertent inclusion of unmonitored agents in agriculture.

\subsubsection{Shifting Livestock Patterns}

Livelihood practices of the people of the HKH fall into three categories (Wu et al. 2016):

- Livelihoods based exclusively on livestock herding

- Livestock herding combined with intensive agriculture

- The practice of mixed crop-livestock systems.

Livestock-based livelihoods (such as the rearing of yak, horse, sheep, and goat) are common in high-altitude areas of the HKH (Berhanu et al. 2007). Access to common-pool resources, such as pasture and water, is fundamental to sustaining this form of livelihood. In the midhills of the $\mathrm{HKH}$, the dominant form of livelihood is the combined practice of rain-fed agriculture (typically maize, wheat, barley, and potatoes) for household consumption and of extensive livestock rearing. Migratory mountain pastoralism, which has been the prevalent form of livestock-keeping in the mountain areas around the Tibetan Plateau, has been 
undergoing drastic changes in terms of spatial and temporal migration patterns, livestock management objectives, and the relationship between crop cultivation and livestock (Yi et al. 2007, 2008).

The practice of sedentary mixed crop-livestock (see Box 12.1) is a dominant form of livelihood in the lower part of the $\mathrm{HKH}$, where traditional agricultural practices like multiple cropping, crop diversification, and conservation-tillage farming are prevalent. Multiple cropping is effective in maintaining agricultural production even under unfavourable climatic conditions. Different crops respond to climatic stressors differently, owing to minimum fluctuation in production and production systems. Conservation farming strives to achieve high, sustained agricultural production, while conserving soil and preserving the local environment. The recognition of the multiple functionalities (including recreation and conservation) of rangelands and other ecosystems in the HKH has also created opportunities for livelihood diversification of pastoral communities. In China, pastoralists in the Tibetan Plateau have been receiving cash stipends for using rangeland resources more sustainably (Yi and Ismail 2011).

Livestock is one of the fastest growing agricultural subsectors in the HKH. Although large ruminants such as cows, buffalo, and yaks make up the majority of the livestock population in the mountains, yak numbers are decreasing in India, Nepal, and Bhutan, while increasing in China (Wu et al. 2016). While elite and higher caste farmers raise large ruminants, poorer and disadvantaged ethnic groups tend to raise smaller animals such as goats, pigs, and poultry (Gurung et al. 2005). For poorer households, these smaller animals are considered important because they require a low initial investment and minimal or no input, and offer a quick return on investment on a continuous basis (Brithal and Taneja 2006; Ali 2007; Gerber et al. 2010; Khan and Ashfaq 2010).

Most goats are raised on marginal land and are a crucial source of livelihood for landless (and nearly landless) farmers and for households headed by women. Goats are a valuable commodity and are considered a source of foreign exchange (APHCA and ILRI 2006). In India, over $70 \%$ of rural households own livestock, and the majority of livestock-owning households keep sheep, goats, pigs, and poultry due to land scarcity, but also for commercial prospects (Ali 2007). According to the Livestock Census (GoP 2006), among all the domestic livestock in Pakistan, goat had the highest growth rate of $3.98 \%$ per year. Pakistan ranks third in Asia in terms of small ruminant population, with an overall annual growth rate of 4\%, the highest in Asia (Khan and Ashfaq 2010). In India, between 1992 and 2003, the poultry population increased by an annual growth rate of $5.9 \%$, whereas the pig and ruminant populations showed only marginal increases (Gerber et al. 2010). The growth in livestock population was driven by rapidly increasing demand for livestock products, population growth, urbanisation, and increasing incomes in developing countries (Delgado 2005; Thornton 2010).

\subsubsection{Livelihood Diversification in the Mountains}

Livelihood diversification is a daily reality for the people of the $\mathrm{HKH}$, and it proves key to buffering against shocks and stresses caused by conflict, market failure, food insecurity, environmental hazards, and climate variability - particularly in a context where informal work and precarious, patriarchal land rights are widespread along with a lack of access to financial instruments and products and other forms of social protection. Population growth has led to land fragmentation and to a significant reduction of grazing area per capita. Over the past three decades, households in the HKH have become somewhat less reliant on land and are increasingly composed of a combination of subsistence farmers and labourers (Herbers 1998). These households no longer rely entirely on their land, yet they cannot subsist without it (Fig. 12.2).

At the macro-economic level, a major shift from agriculture to services and, to a lesser extent, industry is taking place in mountainous countries of the $\mathrm{HKH}$ such as Afghanistan, Bhutan, and Nepal and the HKH areas of China and India (Table 12.1). Despite the fact that this trend is coupled with increased urbanisation and human mobility (Hoermann et al. 2010), the percentage of people dependent on agriculture for livelihoods is still very high.

At the household level, the susceptibility or sensitivity of livelihood to climate-dependent natural resources is a

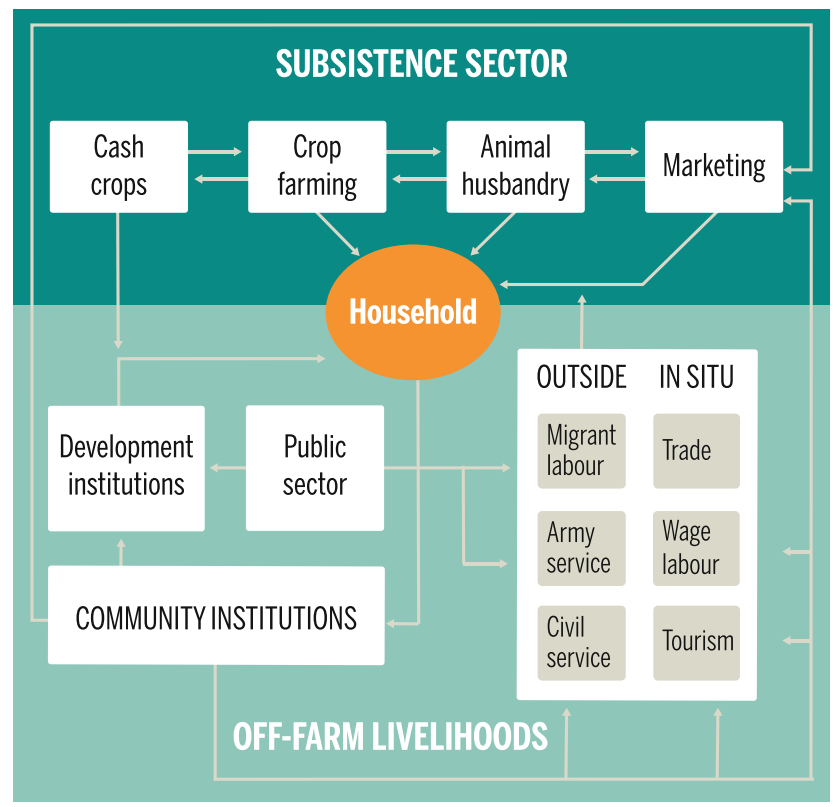

Fig. 12.2 The combined subsistence-labour household 
Table 12.1 Structural evolution of HKH mountain economies (in areas where data is available)

\begin{tabular}{l|l|l|l|l|l|l}
\hline \multirow{2}{*}{ Country } & \multicolumn{3}{|l|}{ Agriculture } & \multicolumn{2}{l|}{ Industry } & \multicolumn{2}{l}{ Services } \\
\cline { 2 - 7 } & 2002 & 2014 & 2002 & 2014 & 2002 & 2014 \\
\hline Afghanistan & 38.5 & 23.5 & 23.7 & 22.3 & 37.8 & 54.2 \\
\hline Bhutan & 27.4 & 17.7 & 38.6 & 42.9 & 35.1 & 39.4 \\
\hline Nepal & 40.8 & 33.7 & 18.1 & 15.6 & 43.3 & 50.7 \\
\hline HP (India) & 23.1 & 15.9 & 36.5 & 41.0 & 39.5 & 42.9 \\
\hline Tibet & 24.5 & 10.0 & 20.2 & 36.6 & 55.3 & 53.5 \\
\hline Yunnan & 20.1 & 15.5 & 40.4 & 41.2 & 39.5 & 43.3 \\
\hline Sichuan & 22.2 & 12.4 & 36.7 & 48.9 & 41.1 & 38.7 \\
\hline
\end{tabular}

Source World Development Indicators (World Bank 2017) HP (Himachal Pradesh), India, data from respective Statistical Handbooks. HP first year is 1999-2000. For China: National Statistical Yearbooks, various issues, National Statistics Bureau

concern for a higher number of households than suggested by macro-economic data on GDP. For instance, a significant part of the service industry in the mountain regions is driven by tourism, which is indirectly dependent on the wellbeing of the natural environment (Isaac 2012).

Ongoing social changes, such as fast-paced urbanisation, (predominantly male) outmigration, and population growth have also been key factors inducing change in traditional crop rotations and pastoral practices (Yi et al. 2007, 2008). The growth of small- and medium-sized towns in the HKH is also helping to spur livelihood options, including opportunities for education, waged employment, and trade.

Most HKH communities tend to rely on mixed rural-urban livelihoods rather than pure rural or pure urban characteristics (The Desakota Team 2008). This has also been inspiring young people to migrate (seasonally) to adjoining towns to seek wage employment while maintaining ties with their homes or to undertake international circular migration (see Chap. 15).

Livelihood diversification can vary according to environmental conditions, access to markets, community resource endowments, cultural norms, and resource governance regimes. The HKH's rich diversity-both biophysical and sociocultural-requires that livelihoods cannot be designed with a one-size-fits-all approach. Location-specific policies and strategies are needed to facilitate the engagement of mountain communities and to promote activities that add value while making communities resilient and sustainable. Understanding the existing livelihood practices and options is central to designing future livelihood strategies. No new approach to diversity should undermine the long-term sustainability of livelihoods.
In the next sections of this chapter, we look into livelihood diversification, turning first to on-farm activities and, subsequently, to off-farm work, focusing on labour migration and tourism.

\subsubsection{On-Farm Activities: The Growing Importance of Medicinal Plants and Future Smart Food}

Appropriately designed livelihood diversification can add value to local economies and increase economic opportunities. For example, milk and meat processing, niche-based high-value crops, or sustainable harvest of herbal and medicinal plants can significantly complement livelihood options for the people of the HKH. In high-altitude areas of Bhutan, China, and Nepal the collection of rangeland products, mostly medicinal plants, has been an important source of household income in recent years. From 1999 to 2007, the average annual contribution of income from yarsagumba (cordyceps sinensis) to agricultural-sector revenue in the Tibet Autonomous Region (TAR) of China was $10.84 \%$ (Wang et al. 2012).

The genetic resources of traditional crops-often referred to as neglected and underutilized food crops (NUFCs) and recently labeled as future smart food (FAO 2017) — are vital for sustainable agriculture (Eyzaguirre et al. 1999; Bhagmal 2007; Padulosi et al. 2011). NUFCs not only play a fundamental role in income generation (Mwangi and Kimathi 2006; Adhikari et al. 2017) and nutrition and food security (Frison et al. 2006; Padulosi et al. 2011; Apeteri 2012; Adhikari et al. 2017), but also hold significant potential for climate-change adaptation (Jarvis et al. 2014).

Some NUFCs are also of great medical importance. For instance, in remote mountain areas, jamun (syzygium cumini) is used to treat diabetes. Likewise, in Gilgit-Baltistan in Pakistan, local people have realized the importance of sea buckthorn for nutritional and medicinal purposes and have expanded the cultivation of this crop (Adhikari et al. 2017).

Among many other traditional crops, millets have been cultivated successfully for millennia, indicating resilience to a variety of conditions and some intrinsic potential for continuous production (Apetrei 2012). Finger millet is a particularly rich source of calcium and iron (Singh and Raghuvanshi 2012). By introducing finger millet into the daily diet of mountain people, common problems in the HKH can be addressed, such as the disorders of bone and teeth caused by calcium deficiency and anaemia caused by iron deficiency. This highlights the importance of NUFCsnot only for food security but also for nutrition (see Chap. 9). With respect to seasonality, buckwheat is preferred in the 
mountains for its fast rate of growth and its weed resistance (Sustainable Agriculture Research and Education n.d.; ICIMOD and GRID Arendal 2014).

NUFCs can make a significant contribution to sustainable nutrition security in the mountains if they are mainstreamed into agriculture, food, and nutrition-security policies and programmes and integrated into local food systems (Adhikari et al. 2017). While not yet a priority for governments in the $\mathrm{HKH}$, the protection and promotion of traditional farming practices and NUFCs (in situ and in vitro) present great opportunities to take advantage of mountain specificities, rather than unsuccessfully seeking to replicate the agricultural intensification approaches designed for the plains.

\subsubsection{Off-Farm Activities: Labour Migration and Agrarian Transition}

Most $\mathrm{HKH}$ countries tend to present mixed rural-urban livelihoods rather than those displaying pure rural or pure urban characteristics. A household may well be physically located in a rural area, but it's likely that it relies on an assortment of livelihoods with urban, rural, and, often, transnational components. This fusion, known as desakota, is widespread in the HKH (The Desakota Team 2008). Young people migrate seasonally to adjoining towns seeking wage employment while maintaining ties with their homes. Labour migration is integral to the portfolio of livelihoods that households rely on to deal with everyday struggles and to shield against various economic, environmental, and social risks (Hoermann et al. 2010; Karki 2012; Gioli et al. 2014a; Banerjee et al. 2016).

Circular labour migration at national, regional, and international scales is particularly widely practiced, mostly by young males who migrate for temporary periods (from months to decades) and send back remittances to their countries of origin (see Chap. 15). Given the lack of access to formal risk-mitigation mechanisms in the region, remittances can be described as a "household sponsored insurance system" (Yang and Choi 2007) and as a substitute for social security (Schrieder and Knerr 2000). Moreover, remittance inflows are untouched by perturbations at the local level and thereby constitute a vital channel of income during and after environmental and political crises (Monsutti 2008; Le De et al. 2013).

Labour migration stimulates flow and exchange of not only financial resources but also ideas and capabilities (social remittances), which influence and often challenge traditional structures at home (IOM 2005). Migration generates financial and human capital, which, if leveraged for development, is a proven driver of poverty reduction. Social remittances can play a particularly important role in development (Hoermann et al. 2010). Three countries in the HKH receive more than $10 \%$ of their GDP from remittances: Bangladesh (11.6\%), Afghanistan (16.3\%), and Nepal (28.5\%) (IFAD 2013). However, remittance economies and overreliance on labour migration are not a sustainable strategy for development. Labour migration is also an extremely costly strategy, which comes at high financial costs (including permits and travel) and high human costs, especially when people migrate to areas where the rights of workers are not guaranteed, such as the Gulf States.

With the exception of China, labour migration is a highly gendered phenomenon in the $\mathrm{HKH}$, predominantly undertaken by young males. However, women's labour migration is on the rise, with women constituting $13 \%$ of the migrant stock in Nepal (CBS 2014; Gioli et al. 2017). While men are absent, women and children take on household responsibilities, including both the productive and domestic roles in tending to livestock and agriculture fields, in addition to taking on work outside the home as labourers (Synnott 2012). The general increase in the workloads of women (resulting from migration and other factors) impinges upon their caregiving roles (Gioli et al. 2014a), exposing women and children to greater threat from water-borne disease (Halvorson 2002). In recounting gendered experiences of change in Baltistan, Azhar-Hewitt (2011) similarly observes the transformation of women's workloads, noting that access to resources and liberties afforded to women in traditional societies are sometimes being denied based upon notions of religiosity and appropriate gender roles, imported in the course of labour migration (see Chap. 14).

Stories of changing gender roles echo across the HKH. In Afghanistan, irrigation water management too becomes a domain with increasing female participation and the intersection of poverty and gender render some women's livelihoods exceptionally vulnerable on account of inability to pay for the petrol for the water pump or community sanction disallowing a woman her share of water (McCarthy and Mustafa 2014).

In the hills of Nepal, most farming households were found willing to neglect farming altogether if alternative sources of income were available to them (Maharjan et al. 2013). Additionally, farmers preferred livestock to crops as a supplement to household income. The share of women in the agriculture sector in Nepal has been $12.6 \%$ higher than that of men, and the participation of women in the agricultural labour force increased from $36 \%$ in 1981 to $45 \%$ in 1991 to $48 \%$ in 2001 (FAO 2010).

The loss of agricultural workforce has also increased the phenomenon of land abandonment in the HKH. Farmers in southeastern Nepal are moving toward the non-farm sector due to low returns on investment (Adhikari and Hobley 2012). This has further intensified migration leading to 
de-intensification of agricultural lands, a trend that is beginning to emerge in other parts of the HKH as well. In Uttarakhand, India, $47 \%$ of respondents identified decreasing agricultural productivity as a major reason for migration (Hoermann et al. 2010; Tiwari and Joshi 2016; Mamgain 2004). With men outmigrating in significant numbers, the bulk of the workload and responsibility falls upon women. Much discussion has taken place on the transformational potential of these shifting roles (see Chap. 14). For instance, a study in northern Pakistan showed that positive gender transformative processes are more likely to be intergenerational and driven by increased access to education for girls (Gioli et al. 2014a).

\subsubsection{Tourism}

Within the wider context of searching for livelihood diversification options, some mountain communities have found opportunities in the recreation and tourism industries. The appeal of recreation in the mountains has long been recognized institutionally, for instance, through the designation of national parks. Tourism has played a significant role in transforming mountain communities around the world, by diversifying local economies, generating employment opportunities, and bringing development to these societies. As the sector builds on natural and cultural heritage values, it can bring the additional benefit of positively impacting conservation.

Mountain specificities that are generally considered constraints to development - including poor accessibility, fragility, and marginality - can be transformed into economic opportunities for tourism (Jodha 1992; Sharma 2000; Nepal and Chipeniuk 2005; Kruk 2010). Tourism intersects with and stimulates a wide range of other sectors in the supply chain, especially agriculture, infrastructure, communications, construction, and handicrafts. Tourism also stimulates a new market for local produce, especially high-value crops. As a complementary livelihood option, the development of tourism will not only generate socioeconomic benefits for the region, but may also address wider social and sociocultural concerns (Kruk 2010). Thus, the tourism industry is being strongly pursued and supported by the HKH governments through their National Development Strategies. For example, in 2016 the Government of Nepal launched the National Tourism Strategy 2016-2025, which envisages a fivefold increase in tourist arrivals by 2025 and includes conservation of cultural heritage and a zero-carbon target as important development goals.

Tourism is not a new phenomenon in the HKH (Karki et al. 2012). Several HKH countries have experienced and benefitted from tourism since the 1970s. Though some countries (such as Bhutan and China) have restricted access to tourists for various political reasons, and others (including Afghanistan, Pakistan, Bangladesh, and Nepal) have seen tourism diminish for periods of time due to political unrest and conflict, the region has generally experienced a strong increase in tourism over the past years. In the HKH countries, ${ }^{2}$ tourism has become the largest service sector, generating much-needed foreign exchange earnings-currently contributing $2-4 \%$ of GDP - and generating $2.8-9.6 \%$ of total (direct and indirect) employment. The tourism industry also involves $0.9-8.3 \%$ of total investment in these countries. Globally, tourism is predicted to continue increasing steadily over the next 10 years, with major new markets on the rise, particularly in Asia (including locations in India and China). While international tourism is sizable and steadily increasing with economic growth in Asia, intraregional tourism markets represent the greatest opportunities for growth. Due to the growing middle class resulting from increasing wealth and better access to credit, regional markets are showing exponential growth. Political liberalization and border-crossing agreements between neighbouring countries (as with Bhutan and India) are also making regional travel easier.

The revival and strengthening of cultural heritage is considered beneficial to tourism (Ganesh and Madhavi 2007; Isaac 2012). In the HKH, old hospitality traditions have been the basis for lodging and other tourist services (such as the concept of teahouses in Nepal), inspiring a special Himalayan mountain-oriented accommodation sector (Odell and Lama 1998).

Tapping the growth of the tourism market within a framework of sustainable development could be an effective mechanism for both enhancing local livelihoods and conserving heritage. However, many challenges remain in realizing such a vision, given the complex cultural, topographical, and political HKH landscape. Therefore, tourism development in the HKH should be approached in a holistic and comprehensive manner to ensure long-term sustainable growth and the resilience of mountain people. Ecotourism, in particular, has the potential to drive sustainable tourism development while providing opportunities for the development of disadvantaged, marginalized, and rural areas, thereby alleviating poverty and stimulating economic development and social wellbeing (Isaac 2012).

\subsubsection{Social Protection Programmes}

Communal property remains an important safety net for mountain communities - particularly for the poorest among them. As even rural communities have become integrated with global economies, the rural/urban distinction has become functionally tenuous at best. As communal property

\footnotetext{
${ }^{2}$ Data based on available national statistics from 2010-12, excluding Afghanistan as tourism in this country is currently minimal (particularly domestic tourism) and limited information is available.
} 
becomes less significant to the livelihoods of more fortunate community members, the strict rules governing use of these assets are eroding (Mustafa and Qazi 2007). The result is that communal land, forest, and rangeland resources are being encroached upon by private interests- to the exclusion of women, children, and poorer members of the community who, lacking food security and social protection, are rendered further vulnerable to various environmental hazards.

The breakdown of traditional risk-sharing mechanisms, along with population growth, urbanisation, and new risks like market volatility and climate change have triggered several formal social-protection initiatives, with social insurance, social assistance, and labour programmes becoming increasingly visible in the HKH's public-policy domain (Wagle 2012). Although these programmes have provided immediate relief to families in need, they are hardly effective in developing the assets and market access necessary for long-term viability of smallholder farmers. There is a strong need to identify innovative, market-based, financial interventions that develop and improve household assets, agricultural entrepreneurial skills, and the resilience of vulnerable communities facing climatic and non-climatic stressors across the HKH.

Social capital is developed by community building achieved through relationships of trust, reciprocity, and exchange, creating links among community members while increasing their access to institutions and government (Ferguson 2012). There are successful examples of development programmes that have leveraged community participation for sustainable use of resources and income-generation activities. For instance, focusing on targeted social assistance, Heifer International $\mathrm{Nepal}^{3}$ has developed the concept of collective enterprise - values-based holistic community development - wherein group members are jointly engaged in sharing responsibility, effort, risk, and profit.

It is important to recognize the significance of targeted social assistance to the poorest section of society. Nepal's community forest user groups (CFUGs) have been mobilized for poverty-alleviation activities and have pioneered the recognition of community forestry as a pro-poor and pro-women programme (Nightingale 2011). There is increasing global recognition of cooperatives as self-help organizations capable of improving livelihoods and wellbeing (Ferguson 2012). Government, cooperatives, and the private sector have been identified as the three major stakeholders in national economic building in Nepal, where the majority of cooperative members are from poor and middle-class households (Bharadwaj 2012).

\footnotetext{
${ }^{3}$ http://heifernepal.org/sites/default/files/AR13_0.pdf.
}

\subsubsection{From Livelihood Diversification to Poverty and Vulnerability Reduction}

Poverty, small holding size, and food insecurity are critical challenges in the HKH, and addressing them calls for a holistic approach. Diversification of farms with high-value crops - while adequately maintaining soil, forests, and other natural resources - is a crucial step in improving the livelihoods of mountain people. In recent years, cash crops such as fruits and vegetables have become prominent in mountain development as a means of improving livelihood options. Livestock, especially small ruminants, have been emerging as a source of cash income for a large number of $\mathrm{HKH}$ farmers. At the same time, urbanisation and demographic changes have introduced new geographic exposure to risk, while conversely providing new opportunities to mitigate risk through enhanced capacity building and skill trainings (Hoermann et al. 2010).

The rigid structure of global markets has the potential to create circumstances of nested vulnerability (Eakin and Bojorquez-Tapia 2008), whereby shocks at the global scale cascade down to affect household and community livelihoods at the local level. There is a need for greater effort in identifying the interconnectedness of global and local processes in order to ensure that strategies for enhancing livelihood options in the HKH also increase the resilience of livelihood systems.

\subsection{Poverty in the HKH: How to Measure and Tackle It}

There are two distinct approaches to measuring human poverty. The first is economic poverty, which is understood as the inability to participate in society due to a lack of resources (Townsend 1979) and is usually measured by household income or consumption. Realizing the limits of such a narrow approach, more holistic ways to measure poverty have emerged over the years, such as multidimensional poverty measures, which is understood to be the failure of basic capabilities to reach certain minimally acceptable levels (Sen 1992) or as a denial of choices and opportunities for living a tolerable life (UNDP 1997).

This chapter considers the multidimensional approach to be more relevant to policy, particularly in the mountain context, as it can more comprehensively capture the complex nature of poverty, thereby better indicating areas for intervention. However, due to data limitations, unidimensional poverty measures based on consumption are used in the first part of this discussion to compare poverty levels across countries and to analyse poverty trends over time. This is followed by a discussion of multidimensional poverty. 


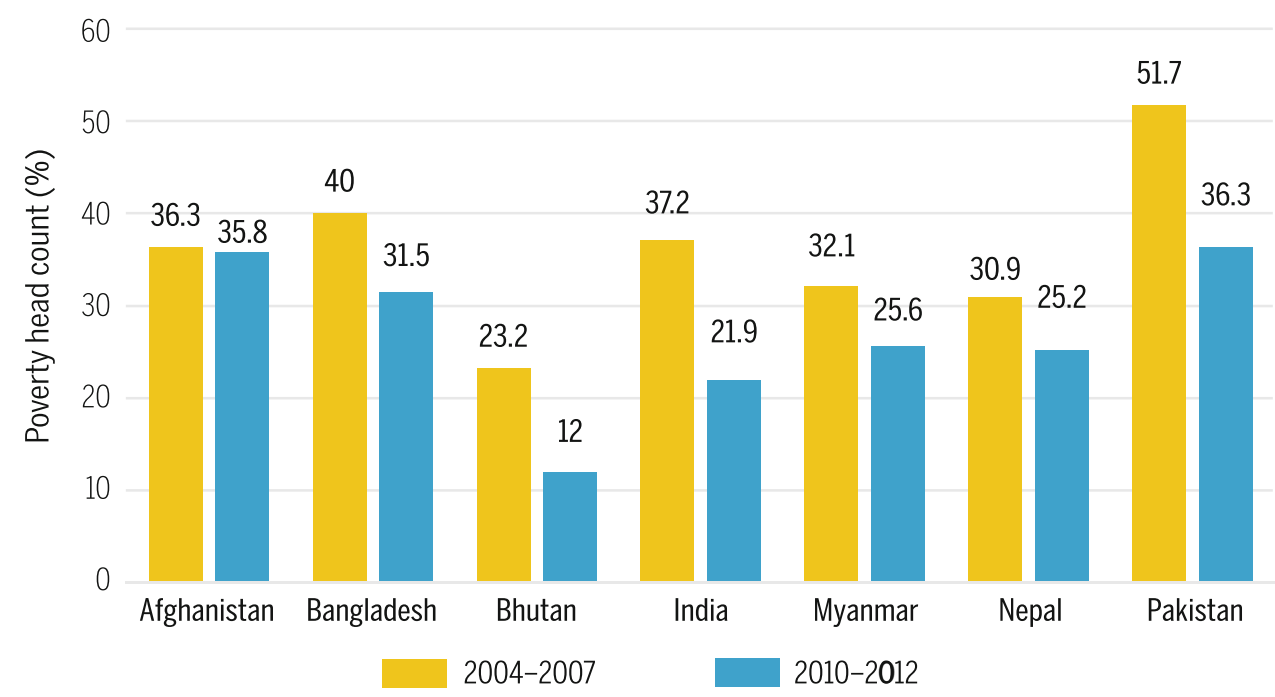

Fig. 12.3 Trend in poverty reduction during the first decade of the 21 st century, national standards (World Bank 2017; http://povertydata. worldbank.org/). Notes 1. The specific years considered for each country are as follows: Afghanistan: 2007, 2011; Bangladesh: 2005, 2010; Bhutan: 2007, 2012; India: 2004, 2011; Myanmar: 2005, 2010;

Nepal: 2010; Pakistan: 2004, 2011. 2. The figures for Myanmar have been taken from a UNDP study conducted for Myanmar using IHLCA (Integrated Household Living Condition Assessment) Survey. (Ministry of National Planning and Economic Development, UNICEF, UNDP, and SIDA 2011: Poverty Profile 2009-2010)

\subsubsection{Mountain Poverty: Specificities and Challenges}

The characteristics of mountain areas that significantly shape development and human life are referred to as mountain specificities. Among these specificities, inaccessibility, fragility, and marginality ${ }^{4}$ are recognized as constraints on development while diversity, biological niches, and adaptation mechanisms are viewed as development opportunities (Jodha 1997). These specificities, combined with the isolated nature of mountain economies, may lead to manifestations of poverty in the mountains that differ from those in the plains. Conventional economic measures of poverty, usually based on income or consumption, fail to capture the complexity of mountain poverty and its noneconomic correlates in these areas. Mountain specificities may hinder the conversion of resources such as income into actual wellbeing outcomes, including adequate nutrition and food security, education, and health (Sen 1999). Thereby, a distinct frame of analysis is needed to understand mountain poverty.

The lack of recognition and understanding of the implications of mountain specificities often leads to misconceptions about the socioeconomic conditions in mountain areas and to misdiagnosis of the sources of poverty (Papola 2002). As a result, the strategies and interventions designed for

\footnotetext{
${ }^{4}$ The mountain areas are marginal and share the attributes of marginal entities due to factors like remoteness and physical isolation, low-productivity resources, or man-made handicaps that prevent mountain areas' participation in 'mainstream' patterns of activities (Jodha 1990a, b).
}

development in mountain areas tend to be unsuitable and, thereby, ineffective.

In the following discussion, we compare economic poverty levels and trends in HKH countries, contrast poverty levels in the mountain areas and the lowlands, and examine poverty incidence among indigenous peoples and the majority populations in China and India.

\subsubsection{Economic Poverty: Levels and Trends in the HKH}

Typically, countries have defined national standards for measuring poverty, most commonly a head-count ratio indicating the proportion of the population below a certain threshold of income or consumption. Such measures are commonly defined as a national poverty line. In addition, international agencies estimate international poverty lines, such as USD 1.25 or 1.90 per capita per day in purchasing power parity terms, leading to comparability of head count ratios across countries.

Using the international poverty line of USD 1.25 per capita per day, ${ }^{5}$ Fig. 12.3 shows income poverty levels in the HKH countries for two time periods - the mid-2000s and 2010-12. Two observations can be made based on these data. First, the incidence of economic poverty at the national

\footnotetext{
${ }^{5}$ The international income poverty line has now been revised to USD 1.90 per capita per day. However, due to data unavailability, we are using the old poverty line (USD 1.25 per capita per day).
} 
Table 12.2 Poverty profile of HKH countries (Hunzai et al. 2011)

\begin{tabular}{|c|c|c|c|c|c|c|}
\hline \multirow[t]{2}{*}{ Country and year of data } & \multicolumn{2}{|c|}{ Total population (millions) } & \multicolumn{2}{|c|}{$\begin{array}{l}\text { Population below } \\
\text { poverty line (millions) }\end{array}$} & \multicolumn{2}{|c|}{$\begin{array}{l}\text { Population below } \\
\text { poverty line }(\%)\end{array}$} \\
\hline & Countrywide $^{\mathrm{a}}$ & HKH areas $^{b}$ & Countrywide $^{c}$ & HKH areas $^{c}$ & Countrywide & HKH areas \\
\hline Afghanistan 2010 & 24.5 & 15.1 & 8.0 & 6.3 & 33.0 & 42.0 \\
\hline Bangladesh $^{\mathrm{d}} 2009$ & 162.0 & 1.33 & 59.9 & 0.6 & 37.0 & 46.0 \\
\hline Bhutan $^{\mathrm{e}} 2009$ & 0.69 & 0.69 & 0.19 & 0.19 & 23.0 & 23.0 \\
\hline China 2009 & 1,331 & 29.4 & 220 & NA & 16.6 & NA \\
\hline India 2009 & 1,155 & 72.3 & 415 & 24.0 & 36.0 & 34.0 \\
\hline Myanmar 2009 & 49.8 & 11.0 & 15.9 & NA & 32.0 & NA \\
\hline Nepal 2009 & 29.3 & 11.8 & 9.0 & 4.7 & 31.0 & 40.0 \\
\hline Pakistan 2009 & 169.7 & 39.3 & 42.4 & 12.5 & 25.0 & 32.0 \\
\hline HKH total/average & 2,921 & 181 & 771 & $61^{f}$ & 26.0 & $31.0^{\mathrm{g}}$ \\
\hline
\end{tabular}

$\mathrm{NA}=$ not available

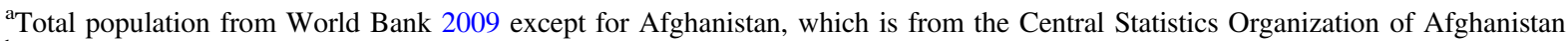

${ }^{\mathrm{b}}$ For updated HKH population see Chap. 1, Box 1.1. This Table has to use the 2009 population figures, as updated information on population below the poverty line in the HKH is not available after 2009

${ }^{\mathrm{c}}$ Figures for population below poverty line from ICIMOD analysis based on NLSS 2003/04, BLSS 2007, NSS 2003, PSLM 2005/06, HIES 2005/06, and NRVA 2007/08 except for China and Myanmar, which are based on secondary sources

${ }^{\mathrm{d}}$ The population of Bangladesh (162 million in 2007) is overestimated, as according to the Bangladesh Bureau of Statistics, the population reached 149.77 million in 2011

${ }^{\mathrm{e}}$ Bhutan lies entirely within the HKH, thus the countrywide and the HKH area figures are the same

${ }^{\mathrm{f}}$ Accurate figures were not available for China and Myanmar; figures were estimated using the same value for the proportion of population below the poverty line as for each country overall, this is likely to be underestimated

${ }^{\mathrm{g}}$ Average of those known and excluding China and Myanmar

level varies widely among the HKH countries. Second, poverty levels are declining over time in all countries, with Pakistan, India, and Bhutan experiencing more rapid decline than the other countries.

\subsubsection{Mountains Versus Plains: Implications for Poverty}

Table 12.2 summarizes the poverty profile of HKH countries and their mountain areas, with figures showing population and the percentage of population identified as living below the national poverty line (Hunzai et al. 2011). The data presented in the table are based on broad assumptions, as the methodologies used to estimate poverty vary by country, and data on population and the percentage of population living below the poverty line were extracted from various sources referring to different years and, thus, not strictly comparable. Nevertheless, they are sufficiently similar to allow for a broad overview.

In 2009, approximately 2.9 billion people were living in the eight countries of the HKH, of which an estimated 771 million were living below the national poverty line; about 200 million people were living within HKH regions of these countries, of which some 61 million were classified as poor. On average, $31 \%$ of the HKH population (excluding China and Myanmar) was below the poverty line, compared with $26 \%$ of the total population of these countries.
Among the HKH countries, Bangladesh had the highest incidence of poverty in the mountain areas $(46 \%)$, followed by Afghanistan (42\%), Nepal (40\%), India (34\%), Pakistan $(32 \%)$, and Bhutan $(23 \%)$. In all countries except India, poverty rates were higher in the $\mathrm{HKH}$ areas than in the country as a whole. In absolute numbers, the Indian Himalayan region had the highest population of poor people in the mountain areas (24 million), followed by Pakistan (12.5 million), Afghanistan (11.3 million), Nepal (4.7 million), Bangladesh (0.6 million), and Bhutan (0.19 million).

In general, there is a dearth of data on poverty levels and trends in the mountain areas of $\mathrm{HKH}$ countries. Gender-disaggregated data are particularly lacking. In the following paragraphs, we compare the incidence of poverty in mountain and non-mountain areas in China, Bangladesh, India, and Nepal with figures based on secondary data.

About $19 \%$ of China's population lives in mountain areas. The incidence of income poverty (measured by the World Bank poverty line of USD 1 per day per capita) in these areas is about twice as high as in non-mountain areas (World Bank 2009) (Table 12.3). Similarly, consumption poverty is three times as high in mountain areas as in non-mountain areas. In Bangladesh, more than $61 \%$ of households are very poor (those without sufficient monthly income to meet food requirements) in the hilly region of Chittagong Hill Tracts compared with $47 \%$ of the households in the valley (ADB 2012) (Table 12.4). 
Table 12.3 Poverty incidence in mountainous and non-mountainous regions of China in 2003 (World Bank 2009)

\begin{tabular}{|c|c|c|c|c|c|}
\hline \multirow[t]{3}{*}{ Region } & \multirow{3}{*}{$\begin{array}{l}\text { Share of national } \\
\text { population }(\%)\end{array}$} & \multicolumn{4}{|c|}{ World Bank poverty line } \\
\hline & & \multicolumn{2}{|l|}{ Income } & \multicolumn{2}{|l|}{ Consumption } \\
\hline & & $\%$ who are poor & $\begin{array}{l}\text { Share of national } \\
\text { population of poor }(\%)\end{array}$ & $\%$ who are poor & $\begin{array}{l}\text { Share of national } \\
\text { population of poor }(\%)\end{array}$ \\
\hline Mountainous & 18.5 & 18.8 & 50.2 & 27.9 & 39.4 \\
\hline Non-mountainous & 54.0 & 6.3 & 49.0 & 14.5 & 59.9 \\
\hline
\end{tabular}

Table 12.4 Poverty incidence by location in Chittagong Hill Tracts, Bangladesh (ADB 2012)

\begin{tabular}{l|l|l|l|l|l|l|l}
\hline Economic status & Hill & Valley & \multicolumn{2}{l}{ Total } \\
\cline { 2 - 8 } & Households & $\%$ & Households & $\%$ & Households & $\%$ \\
\hline Very poor & 1,619 & 61.3 & 1,595 & 47.0 & 3,214 & 53.2 \\
\hline Poor & 777 & 29.4 & 1,476 & 43.4 & 2,253 & 57.3 \\
\hline Better-off & 245 & 9.3 & 328 & 9.6 & 573 & 9.5 \\
\hline Total & 2,641 & 100 & 3,399 & 100 & 6,040 & 100 \\
\hline
\end{tabular}

Table 12.5 Poverty incidence in hill states of India for several years between 1973 and 2012 (Saxena 2016)

\begin{tabular}{l|l|l|l|l}
\hline \multirow{2}{*}{ State } & \multicolumn{4}{|c}{ Percentage of population below poverty line } \\
\cline { 2 - 5 } & $1973-74$ & $1993-94$ & $2004-05$ & $2011-12$ \\
\hline Arunachal Pradesh & 51.93 & 39.35 & 31.10 & 34.67 \\
\hline Assam & 51.21 & 40.86 & 34.40 & 31.98 \\
\hline Himachal Pradesh & 26.38 & 28.44 & 22.90 & 8.06 \\
\hline Jammu and Kashmir & 40.83 & 25.17 & 13.20 & 10.35 \\
\hline Manipur & 49.96 & 33.78 & 38.00 & 36.89 \\
\hline Meghalaya & 50.2 & 37.92 & 16.10 & 11.87 \\
\hline Mizoram & 50.3 & 25.66 & 15.30 & 20.40 \\
\hline Nagaland & 50.8 & 37.92 & 9.00 & 18.88 \\
\hline Sikkim & 50.8 & 41.43 & 31.10 & 8.19 \\
\hline Tripura & 51.0 & 39.01 & 40.60 & 14.05 \\
\hline Uttarakhand & NA & NA & 32.70 & 11.26 \\
\hline India & 54.88 & 35.97 & 37.20 & 21.8 \\
\hline NA $=$ not availate & & & &
\end{tabular}

$\mathrm{NA}=$ not available

In India, the picture is different. In 2011-12, the percentage of mountain people living below the poverty line was higher than the national average in only three of the country's 11 hill states (Table 12.5). Although several hill states in India have poverty rates lower than the national average, hill districts generally face significant development deficits compared with the districts in the plains.

A recent study (Dasgupta et al. 2014) attempted to measure the disparity among these 11 hill states and the six other states primarily classified as plains. Using data for the period 2010-11, this study measured five indicator categories: education, health, economics, infrastructure, and basic amenities. Results indicate that, overall, the states with
Table 12.6 Poverty incidence in Nepal by region 2010-11 (CBS 2011)

\begin{tabular}{l|l|l}
\hline Region & Poverty rate $(\%)$ & Poverty gap (\%) \\
\hline Mountains & 42.27 & 10.14 \\
\hline Hills & 24.32 & 5.69 \\
\hline Terai (plains) & 23.44 & 4.52 \\
\hline Nepal & 25.16 & 5.13
\end{tabular}

a greater proportion of hilly terrain (more than $75 \%$ of the state's total area) fare worse than states with a greater proportion lying within the plains. The highest adverse rankings were observed among the hill states, with the exception of Himachal Pradesh, which scored well.

In India, the hill states also suffer from several challenges that are specific to these states. For example, Nagaland, Arunachal Pradesh, Mizoram, Meghalaya, hill areas of Manipur, and some tribal tracts of Assam have no system of written land records or of land revenue payments. The absence of land records has increased tenure insecurity for the poor due to the growing concentration of land ownership in the hands of a few, resulting in rising rates of tenancy and landlessness, as well as declining output from shifting cultivation. The open-access structural conditions of land cultivation and the fact that the elite are able to corner most government funds have intensified poverty and inequality in these states. The absence of clear property rights has been recognized as a significant cause of degradation of natural resources in hill states.

In Nepal, poverty incidence in mountain areas (42\%) is significantly higher than the national average $(25 \%)$, the midhills (24\%), and the terai (plains) (23\%) (see Table 12.6). The poverty gap index is also higher in 
Table 12.7 Poverty incidence in China by ethnic minority categories in 2003 (World Bank 2009)

\begin{tabular}{|c|c|c|c|c|c|}
\hline \multirow[t]{3}{*}{ Region } & \multirow[t]{3}{*}{ Share of population $(\%)$} & \multicolumn{4}{|c|}{ World Bank poverty line } \\
\hline & & \multicolumn{2}{|l|}{ Income } & \multicolumn{2}{|l|}{ Consumption } \\
\hline & & $\%$ who are poor & Share of poor $(\%)$ & $\%$ who are poor & Share of poor $(\%)$ \\
\hline Ethnic minority & 7.7 & 24.1 & 26.9 & 36.6 & 21.6 \\
\hline Non-ethnic minority & 64.8 & 7.7 & 72.3 & 15.7 & 77.7 \\
\hline
\end{tabular}

mountain areas than in the plains and midhills. The poverty gap index measures the severity of poverty by considering how far, on average, the poor are from poverty line. This figure can be interpreted as the average income shortfall from the poverty line.

\subsubsection{Poverty Rates Among Indigenous Peoples in the HKH}

The HKH is home to millions of indigenous peoples who are among the region's poorest and are politically and socially marginalised. They are variously known in different countries as ethnic minorities, minority populations, and tribal groups. The terms refer to social groups with a cultural identity distinct from the dominant groups, which makes them vulnerable to disadvantage in the development process (IFAD 2002). Table 12.7 presents poverty rates among indigenous peoples and the overall national populations in China.

In China, ethnic minorities are overwhelmingly concentrated in mountainous areas and are significantly poorer than the Han majority - their consumption poverty level is more than twice as high and their income poverty rate is three times as high as that of Han communities (World Bank 2009). In rural areas, ethnic minorities have less access to wage employment and earn less when they engage in wage employment (Hannum and Wang 2012). Enrolment rates among school-aged children are lower among minority populations than among Han populations. Also, minority areas have less developed healthcare infrastructure and less access to safety nets such as unemployment and pension insurance. Therefore, it is important that poverty reduction efforts complement programmes to improve physical and social infrastructure in the remote areas inhabited by ethnic minorities.

\subsubsection{Existing Multidimensional Poverty Measures}

Stemming from the pioneering work of Amartya Sen, in the 1980s an increasing number of scholars disputed the idea that command over monetary resources could provide an adequate informational basis to evaluate human wellbeing, arguing that a broader lens was needed in assessing poverty.
The UNDP's human development index (HDI) (UNDP 1990) and human poverty index (HPI) (Anand and Sen 1998; UNDP 1998) were the first attempts to formalize the inclusion of non-income components in respectively defining global development and poverty through the inclusion of education and health in the assessment. Subsequently, the multidimensional poverty index (MPI) (Alkire and Santos 2010; UNDP 2010) was developed to assess multiple deprivations in education, health, and the standard of living.

The MPI aggregates household-level data on 10 indicators: years of schooling, child enrolment, child mortality, nutrition, access to and type of electricity, drinking water, sanitation, type of flooring, cooking fuel, and assets. The MPI is derived as the product of the number of people living in multidimensional poverty and the average intensity of deprivation as measured by indicators (Alkire and Santos 2010).

Hence, the MPI presents the percentage of population living in multidimensional poverty adjusted by the intensity of the deprivation. The detailed methodology and global estimates are available elsewhere (Alkire and Foster 2011; Alkire et al. 2015). The use of data from household surveys allows for disaggregation at the subnational level to highlight poverty patterns in terms of geography or household characteristics. Furthermore, the MPI can be deconstructed by dimension, allowing for identification of the main aspect of deprivation in a given population.

Table 12.8 presents the multidimensional poverty head count ratio, the average intensity of poverty, and the multidimensional poverty index in eight HKH countries. Data were drawn from the 2015 Human Development Report (UNDP 2015), except for Myanmar, for which figures have been estimated using the Poverty and Vulnerability Assessment Survey 2013 (Gerlitz et al. 2014). The estimates are compared with the human development index and rank for 2013.

Table 12.8 illustrates three key contributors to multidimensional poverty. As per the case of income poverty, the estimates are not strictly comparable due to dissimilarity of indicators used, varying data sources, geographical coverage within countries, and varying time period. However, all the estimates are based on the Alkire and Foster methodology and provide a broader prospective of multidimensional poverty. 
Table 12.8 Multidimensional poverty indices in HIMAP countries

\begin{tabular}{|c|c|c|c|c|c|c|c|c|}
\hline \multirow[t]{2}{*}{ Country } & \multirow[t]{2}{*}{$\begin{array}{l}\text { Year and data } \\
\text { source }\end{array}$} & \multirow[t]{2}{*}{$\begin{array}{l}\text { Multidimensional } \\
\text { poverty }(\%)\end{array}$} & \multirow{2}{*}{$\begin{array}{l}\text { Intensity } \\
\text { of } \\
\text { deprivation }\end{array}$} & \multirow[t]{2}{*}{$\begin{array}{l}\text { Multidimensional } \\
\text { poverty index }\end{array}$} & \multicolumn{3}{|c|}{$\begin{array}{l}\text { Contribution of deprivation to } \\
\text { multidimensional poverty }\end{array}$} & \multirow{2}{*}{$\begin{array}{l}2014 \text { HDI } \\
\text { value } \\
\text { (rank) }\end{array}$} \\
\hline & & & & & $\begin{array}{l}\text { Education } \\
(\%)\end{array}$ & $\begin{array}{l}\text { Health } \\
(\%)\end{array}$ & $\begin{array}{l}\text { Living } \\
\text { standard } \\
(\%)\end{array}$ & \\
\hline Afghanistan & 2010-11, MICS & 58.8 & 49.9 & 0.353 & 45.6 & 19.2 & 35.2 & $0.465(171)$ \\
\hline Bangladesh & 2011, DHS & 49.5 & 47.8 & 0.237 & 28.4 & 26.6 & 44.9 & $0.570(142)$ \\
\hline Bhutan & 2010, MICS & 29.4 & 43.5 & 0.128 & 33.1 & 24.8 & 42.1 & $0.605(132)$ \\
\hline China & 2012, NS & 5.2 & 43.3 & 0.023 & 30.0 & 36.6 & 33.4 & $0.727(90)$ \\
\hline India & 2005-06, DHS & 55.3 & 51.1 & 0.282 & 22.7 & 32.5 & 44.8 & 0.609 (130) \\
\hline Nepal & 2011, DHS & 41.4 & 47.4 & 0.197 & 27.3 & 28.2 & 44.5 & $0.549(145)$ \\
\hline Pakistan & 2012, DHS & 45.6 & 52.0 & 0.237 & 36.2 & 32.3 & 31.6 & $0.538(147)$ \\
\hline $\begin{array}{l}\text { Myanmar (Shan and } \\
\text { Chin states only) }\end{array}$ & 2013, PVA & 53.5 & 39.3 & 0.21 & 29.0 & 19.5 & 42.8 & $\begin{array}{l}0.536^{\mathrm{a}} \\
(148)\end{array}$ \\
\hline
\end{tabular}

Source Human Development Report 2015; PVA: Poverty and Vulnerability Assessment Survey 2013

Notes MICS: multiple indicator cluster survey; DHS: Demographic and Health Survey; NS: national surveys (only nine provinces)

${ }^{\mathrm{a}}$ For the entire country

The extent of multidimensional poverty varied from $5 \%$ in China to $59 \%$ in Afghanistan. In all countries except China and Bhutan, the multidimensional poverty rate was well above $40 \%$. Though the extent of multidimensional poverty varied widely across countries, the average intensity of poverty was fairly consistent, ranging from $43 \%$ in both Bhutan and China to $52 \%$ in Pakistan. The multidimensional poverty index was lowest in China $(0.02)$ followed by Bhutan (0.13), and it was highest in Afghanistan (0.35) followed by India (0.28). The comparison of MPI with HDI revealed that the ranking of HDI and MPI are not necessarily similar. Though India ranked second in HDI among eight countries, it ranked seventh in MPI.

Given its global focus, the MPI inevitably loses context-specificity. This issue is particularly salient in the context of mountain areas due to the unique nature of mountain poverty and its variation across countries in the HKH. Country-level estimates may mask significant inequalities between mountainous and non-mountainous regions-as well as inequalities among mountainous areas. While the availability of different, country-specific estimates of multidimensional poverty are increasingly available for developing countries, including some within the HKH (Alkire and Seth 2013 for India; Roche and Santos 2013 for Bangladesh; Santos 2013 for Bhutan; Trani and Bakshhi 2013 for Afghanistan; Mitra 2014 for Nepal; OPHI 2016 for Pakistan), thus far only one study (of Nepal) has addressed the complexity of capturing multidimensional poverty in mountainous regions (Gerlitz et al. 2015a). Box 12.2 presents an example of disparities within a given country, in the context of two provinces in Myanmar. A further gap in the evidence base relates to the decomposition of deprivations within the household based on, for instance, gender and age.

\section{Box 12.2 Multidimensional poverty in Shan and Chin States of Myanmar}

In Myanmar, the states of Shan and Chin are of particular interest, as they are largely mountainous and poorly accessible. Shan accounts for $11 \%$ of Myanmar's population, while Chin accounts for about $1 \%$. In 2011, the national poverty rate in Myanmar was $26 \%$ while the poverty rate was $33 \%$ in Shan and $73 \%$ in Chin (UNDP 2011).

Using ICIMOD's Poverty and Vulnerability Assessment survey data, Mohanty et al. (2018), estimated the extent of multidimensional poverty in Shan and Chin, measuring education, health, standard of living, energy, water, sanitation, and access to services through 12 indicators. The aggregation of these measurements was based on MPI methodology. Figure 12.4 presents the comparison of consumption poverty and multidimensional poverty in Shan and Chin. The multidimensional head-count ratio and index value were, respectively, $49 \%$ and 0.21 in Shan and $75 \%$ and 0.32 in Chin. The composition of poverty differed in the two provinces, with education and health contributing one-third to multidimensional poverty in Shan and Chin, respectively. The estimated populations of multidimensional poor and consumption poor were consistent in the case of Chin, but in Shan the multidimensional estimate indicated a much larger poor population than the consumption-based measure, with $28 \%$ of the state population considered poor by multidimensional assessment though not considered poor in terms of consumption alone. 


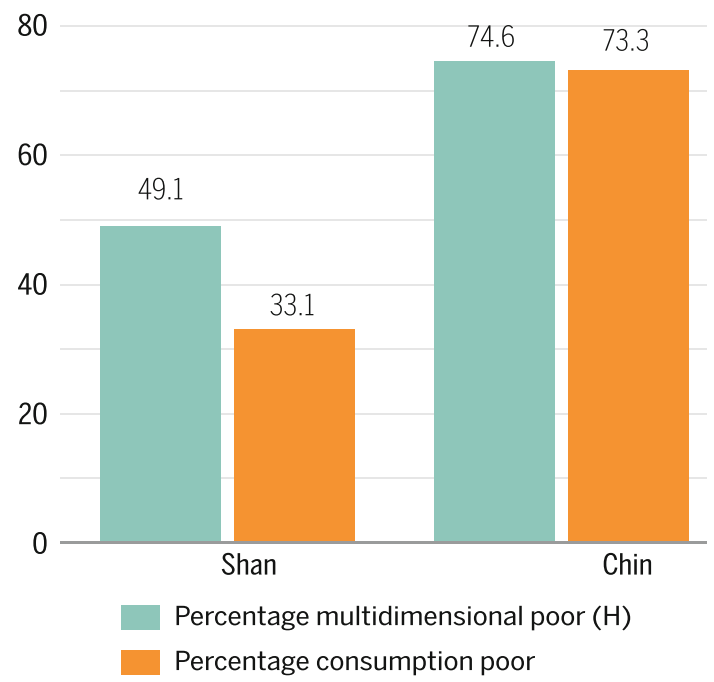

Fig. 12.4 Percentage of multidimensional poor and consumption poor in Shan and Chin in 2013 (Source based on data presented in Table 3 in Mohanty et al. 2018)

\subsubsection{Determinants of Poverty in the HKH}

While poverty is generally associated with social status (class, caste, ethnicity), education, employment status, and occupation, human wellbeing in mountain areas is also inextricably linked to the so-called mountain specificities, conditions including inaccessibility, fragility, marginality, diversity, biological niches, and human adaptation mechanisms (Jodha 1992; Hunzai et al. 2011). Factors that predict poverty and its persistence can be broadly summarized by the following categories (Hunzai et al. 2011; Gerlitz et al. 2012; Gerlitz et al. 2014; See Box 12.3):

- Remoteness and poor accessibility to basic facilities and markets

- Access to and dependence on natural resources

- Demographic factors

- Cultural and social factors

- Lack of empowerment.

In the $\mathrm{HKH}$, mountains provide ecosystem services on which many communities are directly or indirectly dependent. Notably, the most obvious dependence is seen among the rural poor who are often dependent on natural resources to meet their requirements for food, fodder, shelter, and energy. The rural mountain poor include pastoralists, herders, small farmers, and forest dwellers. The cultural and recreational services provided by the surrounding environment also constitute a fundamental aspect of mountain life and culture. Indirect regulating services ensuring hydrological services, soil fertility, protection from erosion, microclimatic stabilization, pollination, and the conservation of biodiversity are also important — not only for those in the immediate area but also for those who are located in relatively distant or downstream areas.

Box 12.3 The multidimensional poverty measure for the Hindu Kush Himalaya: the case of Nepal

The Multidimensional Poverty Measure for the Hindu Kush Himalaya (MPM-HKH) was specifically designed to identify and describe multidimensional poverty in a region that is predominantly rural and mountainous - and covers several of the world's least developed countries (Gerlitz et al. 2015a). It incorporates 16 indicators that capture deprivations in seven dimensions identified through literature review (Gerlitz et al. 2014), data analysis (Hunzai et al. 2011; Gerlitz et al. 2012), and consultation with experts. These dimensions are: education, health, material wellbeing, energy, water and sanitation, social capital, and access to services. They are aggregated using MPI methodology.

The MPM was applied to 23 districts of Nepal, which showed wide variation in the magnitude and composition of multidimensional poverty. The poverty status in the mountains and hills was highly heterogeneous, showing some of the poorest as well as the best-off districts (see Fig. 12.5), which might be explained by the fact that some mountain and hill areas are very remote, while others are well connected or hotspots of tourism. The findings also revealed common patterns in the profile of mountain poverty, such as the frequency with which lack of access to services is the dominant dimension of poverty in mountainous areas (see Fig. 12.6).

The study illustrates the importance of location-specific data in the development of effective poverty reduction strategies. Blanket, country-level approaches are likely to miss crucial local manifestations of poverty and, thus, are likely to be less effective.

According to poverty reports from the HKH countries, households that mainly depend on agriculture face higher risks of falling below the poverty line than households with additional income sources. Due to insufficient agricultural land, changes in agricultural productivity, small and fragmented landholdings, lack of irrigation, lack of mechanization, barriers to market participation, and falling commodity prices, the mountain areas constitute a challenging environment for agriculture (Tulachan 2001; Goodall 2004; Ediger and Huafang 2006). Several studies have mapped the nature and extent of dependence on natural resources among the region's most deprived populations (Shah 2009). 
Fig. 12.5 MPM-HKH index value, headcount, and intensity by district (Gerlitz et al. 2015a, p. 283)

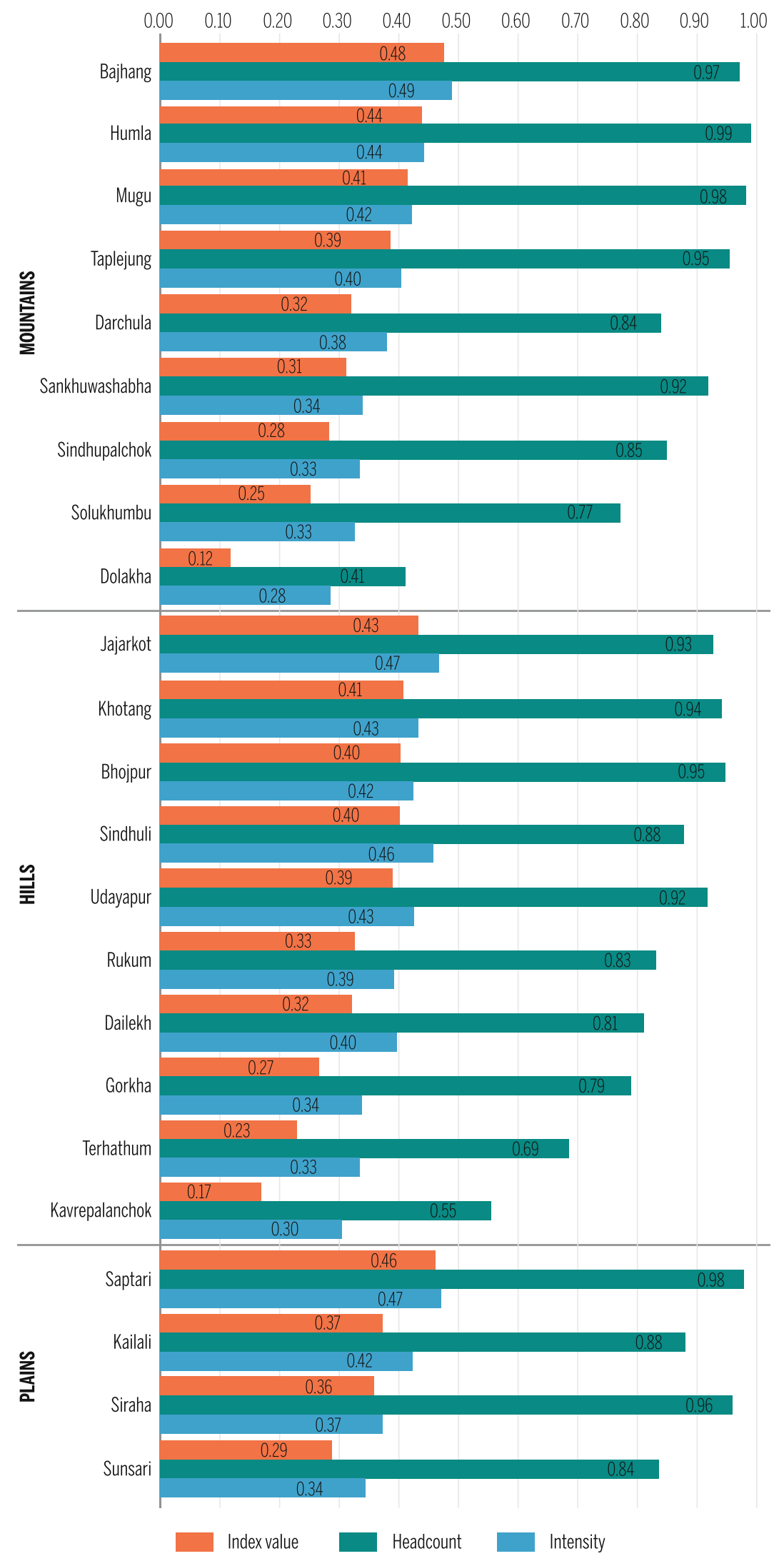


Fig. 12.6 MPM-HKH relative contribution of poverty dimensions by district (Gerlitz et al. 2015a, p. 284)

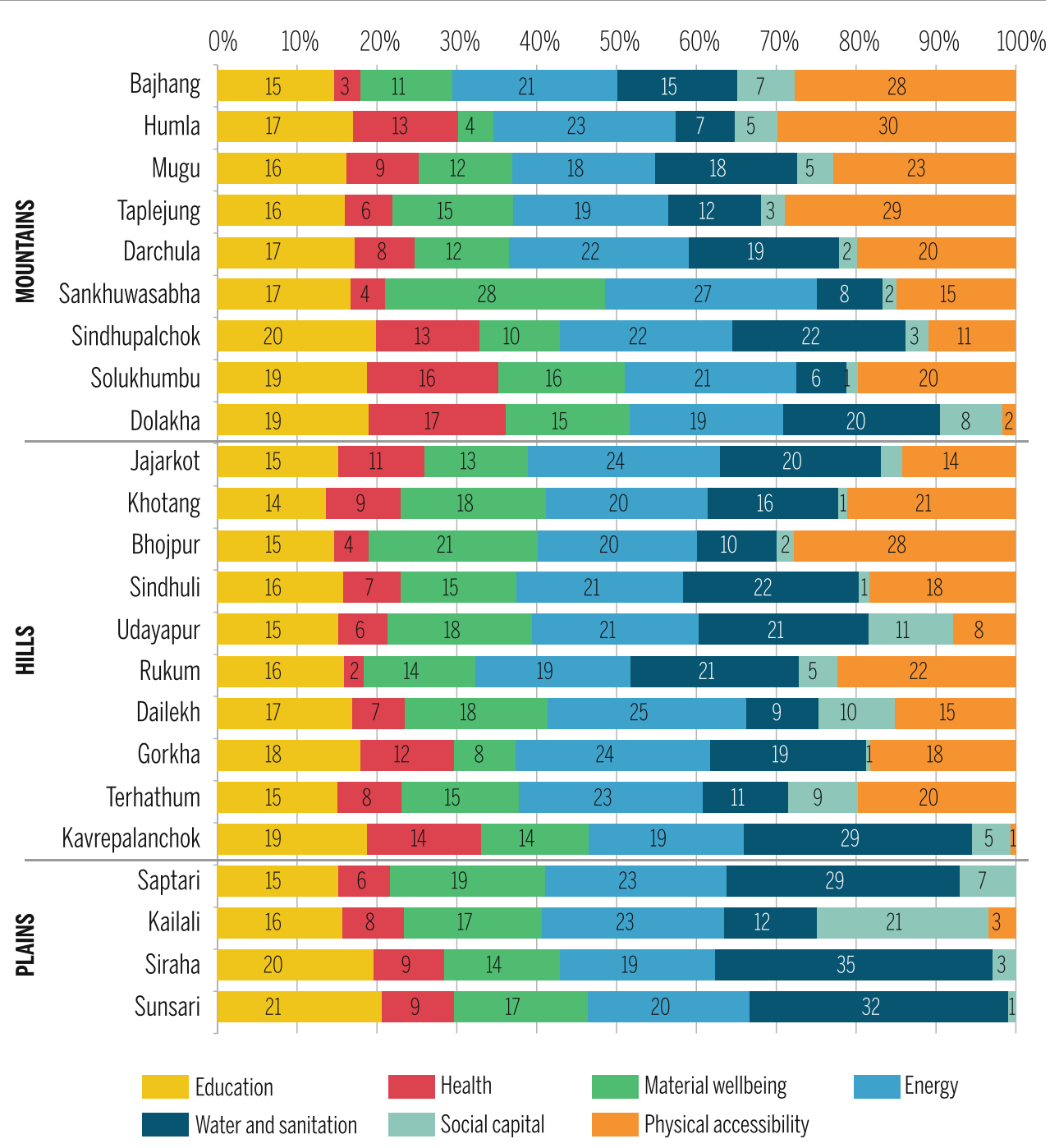

However, evidence from the region does not conclusively establish how such dependence might be disrupted by human interventions or changes in natural circumstances. Equally debated is the issue of whether the poor's sustained dependence on natural resources works against conservation of natural resources in South Asia, particularly in light of climate change or natural hazards.

Household demographic characteristics, such as adverse dependency ratios (particularly in the presence of migration) (Kaspar 2005; Hoermann et al. 2010; Banerjee et al. 2011; Gerlitz et al. 2012), and cultural norms that limit access by women, minority groups, and lower castes to resources and basic services have been identified as key predictors of poverty and deprivations (de Haan 1999; Bird et al. 2002). A potential, although understudied, determining factor of poverty is the lack of empowerment within remote mountain communities and the district government's lack of accountability to them.

Infrastructure has significant effects on economic wellbeing (Ali and Pernia 2003). In regions such as the HKH, the availability of public infrastructure is limited by geographical conditions (Escobal and Torero 2005), which also limit the spread of economic activity through the region. For instance, examining the role of geography in regional inequality, welfare, and development, Kanbur and Venables (2005a) found a strong correlation between geography and development. Huge welfare disparities and a high concentration of very poor people exist across the most geographically adverse regions. In summarizing findings from studies in 26 countries, Kanbur and Venables (2005b) found public infrastructure to be a key explanatory factor underlying the level and trend of spatial inequality in a country.

Inaccessibility permeates all of the HKH countries and contributes to the poverty levels observed across economies (Hunzai et al. 2011; Gerlitz et al. 2012). Several studies have noted the impact of remoteness, which often results in poor connectivity in terms of transport and roads, limiting access to markets and to locations with alternate means of employment, better healthcare, and education facilities. Due to elevation alone, mountain areas can face development 
costs that are two to three times higher than in the plains (Dasgupta et al. 2014). Poverty in mountain areas results not only from poor resource endowments of individual households but also from the severe constraints of unfavourable geographical situations. As a result, poverty usually affects the entire population of a mountain area while it only affects some households in a lowland area. Although there is some variation in income among households and groups in mountain areas, it is less distinct than in the plains. This unique characteristic has been recognized in China's poverty reduction approach, which targets poor areas rather than poor people in development programmes.

Due to the unique terrain and climate conditions in mountain areas, people require a higher caloric intake, warmer clothing, and permanent shelter to protect themselves from extreme weather, as compared to people in the plains. Standardized national poverty lines may not capture these specific needs, leading to failure in identifying many mountain people as poor and in need of additional resources to obtain the same degree of wellbeing (such as being well-nourished or having decent shelter). With greater requirements for food, clothing, and shelter in mountain areas (and the higher cost of goods in these areas), the deficiency in meeting requirements for basic wellbeing - and the incidence of poverty-would understandably be greater.

In most cases, mountain areas also suffer from political, social, and economic marginalization due to their remote location, low population, and indigenous cultures. As a result, mountain peoples are seldom involved in national political and policy-making processes. This results in a lack of representation in the national agenda, leading to a sense of exclusion and lack of empowerment among these mountain populations, which adds a psychological dimension to their poverty (Blaikie and Sadeque 2000). People in mountain areas (particularly women) face severe strain in securing basic necessities, such as water, fuelwood, and fodder for livestock. Furthermore, many agricultural operations must be carried out manually due to the difficult terrain. The resulting hazards, physical strain, and drudgery, which are specific to mountain poverty, are not reflected in the commonly used indicators.

In mountain areas, livelihoods are highly vulnerable due to the limited resource base, fragility of resources and environment, and lack of transport due to difficult terrain. The high incidence of natural hazards often damages the means of livelihoods such as agricultural lands, irrigation channels, and crops, as well as houses, transport, and communication facilities. As a result, the maintenance of livelihoods is highly precarious and the risk of people falling into poverty is much higher than in the lowlands.

There are cultural norms among ethnic minorities in mountain areas that may disfavour particular groups (such as women and indigenous peoples). However, among some ethnic minorities that are matrilineal, women tend to have greater access to resources than men. For example, among the matrilineal Khasi tribe in Meghalaya, India, women have greater access to land and property than men.

Table 12.9 presents the findings from Hunzai et al. (2011) and Gerlitz et al. (2012), who studied selected potential drivers of income poverty, using national-level data disaggregated by mountain and non-mountain areas in Afghanistan, Bangladesh, Bhutan, India, Nepal, and Pakistan. The table highlights remoteness, lack of access to services, and lack of education as key drivers of poverty in mountain regions, but it also shows that mountain regions are not always at a disadvantage in comparison to the plains. These findings also show a lot of variation in the selected indicators - across and within countries (such as India) which calls for context-specific analysis and policies. This table also shows that surveys and databases are far from harmonized; information on key potential drivers of poverty (such as dependence on natural resources, social status, or empowerment) is lacking, or can be strengthened. Finally, it shows there is a need for longitudinal data and constant monitoring to shed light on poverty in the $\mathrm{HKH}$, allowing for better understanding of such dynamics as the duration of poverty spells and the causes of transitions in and out of poverty.

\subsection{Social Vulnerability in a Changing Climate: Why It Matters in the HKH}

Mountain livelihoods are highly vulnerable to the impacts of climate and environmental change. Vulnerability-while explained in different ways - generally refers to the extent to which socio-ecological systems are susceptible to and able to cope with the pressures and shocks of climate change (Füssel and Klein 2006). From a hazards perspective (see Chap. 11), vulnerability is the susceptibility of an individual or a group to suffer damage from environmental extremes and from a relative inability to recover from that damage (Mustafa et al. 2011). While the biophysical impacts of climate change have received considerable policy attention, the political, economic, and social impacts are relatively underexplored, yet very important (Adger 2006).

Vulnerability is embedded in everyday power dynamics; thus, its exposure and intensity varies according to political economy, social capital (Pelling and High 2005; Turner 2016), gender (Sultana 2014; Morchain et al. 2015), and ethnicity (Bolin 2007), among other factors. Adger and Kelly (1999) link collective social vulnerability with a lack of institutional and market structures, such as infrastructure, insurance, and social security. An individual's social vulnerability is linked to social status, access to resources, and a diversity of livelihood strategies (Adger and Kelly 1999). 
442

G. Gioli et al.

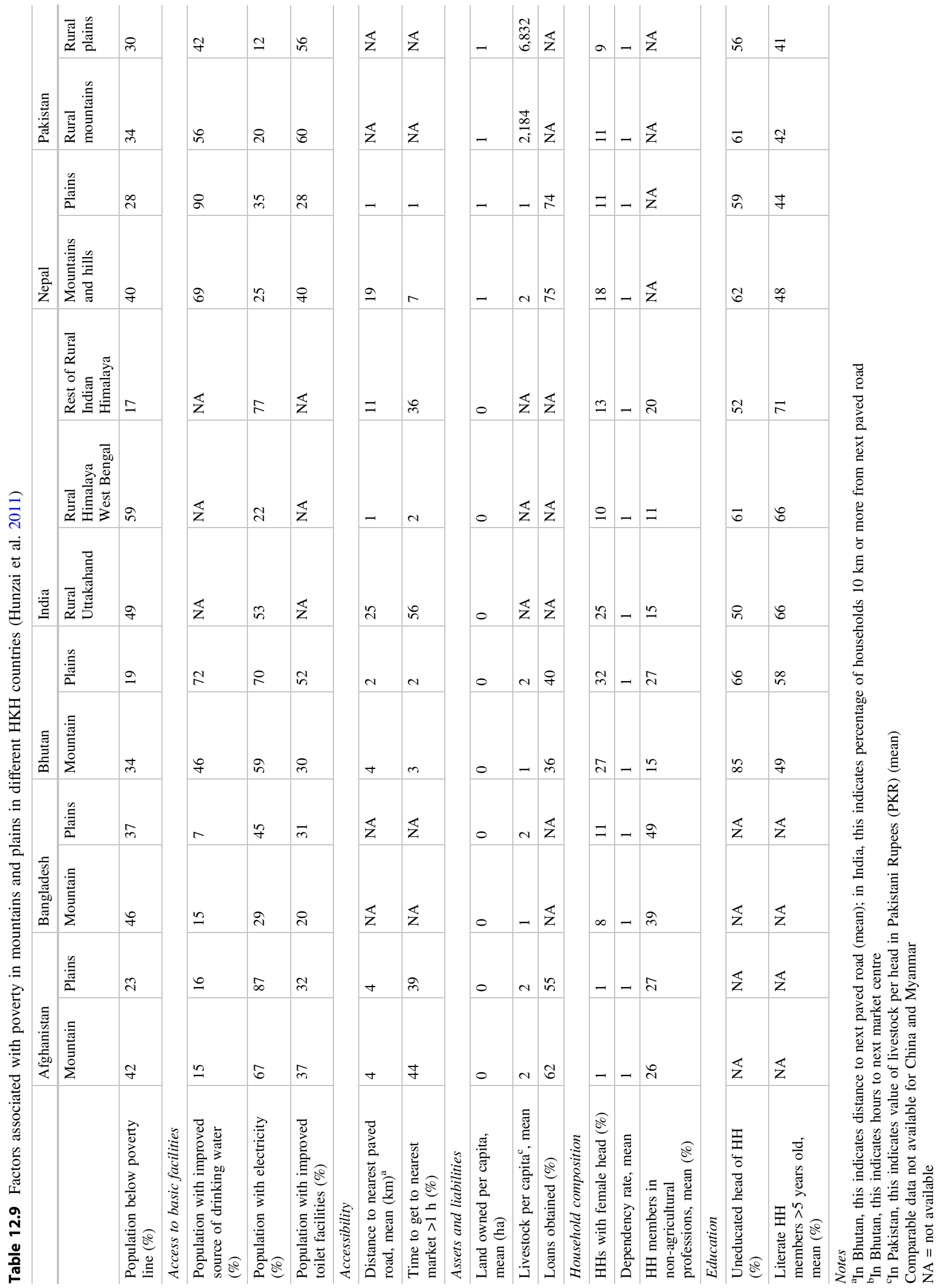


This chapter utilizes Cutter's (1996) integrative concept of 'vulnerability of place', which looks at the aggregate of biophysical risk and socioeconomic factors within a geographical area to determine vulnerability. Thus, vulnerability is a function of external factors (such as exposure to environmental shocks and stresses) as well as internal factors (such as sensitivity to change and adaptive capacity). Importantly, this understanding posits vulnerability to climate change as dynamic, varying according to economic, social, geographic, demographic, cultural, institutional, governmental, and environmental factors (IPCC 2012).

\subsubsection{How to Measure Vulnerability}

To understand the nature of vulnerability to climate change as it impacts local livelihoods, a number of efforts have been made to measure vulnerability. While early vulnerability measures were primarily scientific biophysical assessments of climate change impacts, these measures evolved into more integrated, policy-driven vulnerability assessments that take political, economic, and social drivers into account. This discussion will first review qualitative vulnerability assessments before moving on to quantitative assessments, such the Climate Vulnerability Index (CVI) and the multidimensional livelihood vulnerability index (MLVI), emphasizing work done in mountain areas.

There are several methods of vulnerability and capacity analysis that have been used by international organizations in post-disaster and climate change planning. The Climate Vulnerability and Capacity Analysis (CVCA) is useful as it prioritizes local knowledge on climate change and adaption strategies in the data gathering and analysis process, integrating community knowledge and scientific data to better understand local impacts of climate change. The CVCA tools facilitate a participatory process for multi-stakeholder analysis and collaborative learning to qualitatively address the underlying causes of vulnerability (Dazé et al. 2009).

The Participatory Climate Risk Vulnerability and Capacity Assessment (PCR-VCA) is another useful methodology, as it incorporates an assessment of hazards within the community when evaluating its overall risk context, its livelihood assets base, and the enabling environment (Regmi et al. 2010). ICIMOD's Community-Based Climate Vulnerability and Capacity Assessments in Mountain Areas provides the most relevant analytical framework for understanding vulnerability in the $\mathrm{HKH}$, as it takes mountain specificities into account.

The framework documented in Fig. 12.7 addresses the impacts of climate change variability and non-climatic factors (environmental, economic, social, demographic, technological, and political) and the extent to which these may have adverse or beneficial impacts on a community's exposure, sensitivity, and adaptive capacity (Macchi 2011). This model takes into account an individual's, household's, or community's inherent capacity to adapt to climate change impacts (Füssel and Klein 2006). While adaptive capacity refers to the potential to adjust (see Chap. 13), adaptation is the action of adjustment, which in the context of mountain areas is often a survival practice or a coping strategy (Macchi and Gurung 2015). The Vulnerability and Capacity Assessment (VCA) approach documented above combines a conceptual assessment of vulnerability with the Sustainable Livelihoods Approach (SLA), as shown in Fig. 12.8. The SLA is helpful in understanding vulnerability, as
Fig. 12.7 Conceptual framework for vulnerability (Macchi 2011, adapted from Füssel and Klein 2006)

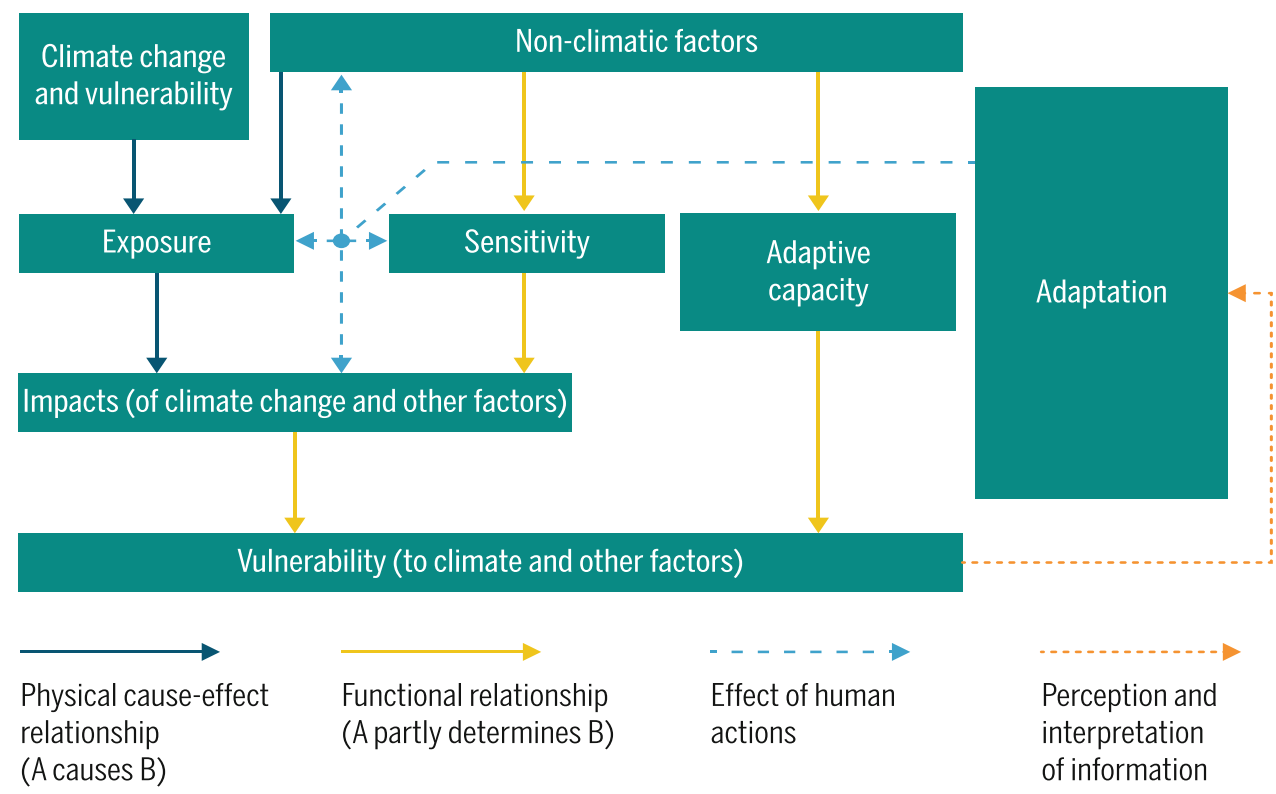


Fig. 12.8 Sustainable livelihoods approach (Macchi 2011, adapted from DFID 1999)

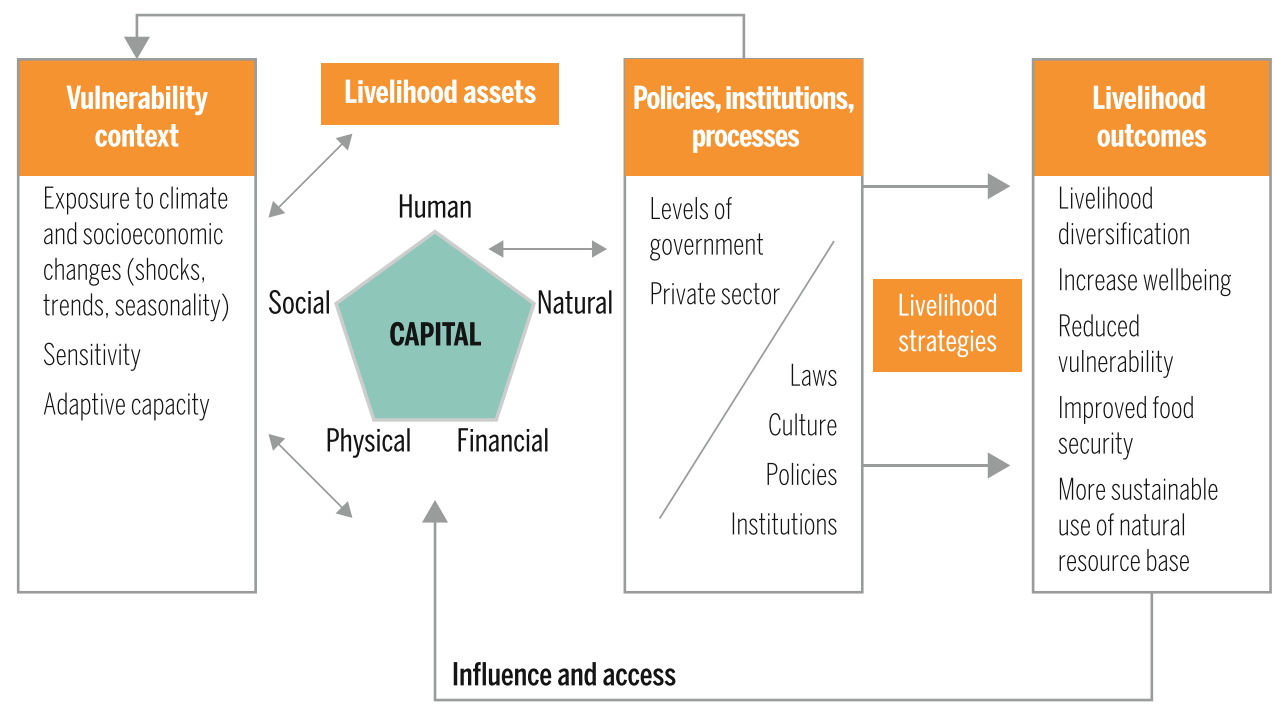

livelihood assets and capabilities are key determinants of a community's capacity to adapt to climate and socioeconomic change (Macchi 2011).

By understanding communities' natural livelihood assets and capacities, it is possible to develop livelihood policies, strategies, and institutions to improve community resilience while fostering livelihood diversification, increased wellbeing, reduced vulnerability, improved food security, and more sustainable use of the natural resource base (Macchi 2011). In Macchi's (2011) VCA, data was collected at community and household levels through participatory rural appraisal, household interviews, and focus group discussions. Attention to gender and marginalized social groups (such as minorities and indigenous peoples) is central to the process, as these groups generally have a weaker livelihood assets base.

Mountain communities have long histories of adapting to extreme environmental conditions and usually base their adaptive strategies on their livelihood assets, particularly their human, social, and natural capital. However, these communities often lack access to financial and physical capital due to their marginalization, isolation, and the fragility of the ecosystems they inhabit, all of which hamper their capacity to adapt (Macchi 2011).

In Uttarakhand, India, the VCA showed that communities already perceived a decrease in rainfall, unpredictable onset of the monsoon, longer dry spells with drought-like conditions, higher temperatures linked with decreased water availability, and warmer winters with less snowfall. These factors have impacted livelihood systems by causing a decline in agricultural productivity, drier streams, less productive lands, and increased incidence of pests and disease. While communities are actively adapting by replacing crops and shifting to smaller livestock, there is future risk of increased insecurity in food and livelihood (Macchi 2011). In a later study conducted in 20 villages in northwest India and across Nepal, Macchi and Gurung (2015) found that many of these coping strategies and adaption mechanisms would not be sustainable in the face of future climate change and were restricted to social groups with appropriate assets. Social markers at the intersection of class, caste, gender, and ethnicity were found to be key factors in determining vulnerability.

\subsubsection{Linking Poverty and Vulnerability: Quantitative Vulnerability Assessments}

Much of the literature on vulnerability is case-based and discussed in narrative form, as there are many challenges in developing standardized measures of vulnerability across diverse landscapes and social settings. Yet, as in the case of poverty assessment, there have been attempts to measure vulnerability quantitatively in order to achieve a more objective and comparable analysis across spatial and temporal scales.

A number of efforts have been made to measure vulnerability through indices, which use theoretical models to analyse the impacts of composite variables. Many of these studies follow the Alkire-Foster method, discussed earlier, in analysing multidimensional poverty (Alkire and Foster 2011).

Pandey and Jha (2011) proposed a Climate Vulnerability Index (CVI) that incorporates at the household level the three dimensions of vulnerability identified by the IPCC exposure, sensitivity, and adaptive capability - to assess a community's overall vulnerability to climate change. The index defines and measures exposure as natural hazards and climate variability measurements; sensitivity as health, food, and water variables; and adaptive capability as metrics of socio-demographics, livelihood strategies, and social 
networks (Pandey and Jha 2011). The CVI ranges from high (0) to low (1) vulnerability and can be used in monitoring vulnerability fluxes under stress conditions or in evaluating proposed programmes or policy interventions by altering variables and comparing the output to the baseline (Pandey and Jha 2011). The study's authors applied the CV to the Indian Himalaya (Srinigar, Uttarkhand) and a major finding was that vulnerability (sensitivity and adaptive capacity) was higher in areas farther from the district headquarters, as compared with closer areas, while exposure was comparable despite distance.

The vulnerability and capacities index (VCI) proposed by Mustafa et al. (2011) may be quite useful in the HKH. Following Woodrow and Anderson (1989) this VCI breaks vulnerability into three broad categories of material, institutional, and attitudinal vulnerability. The VCI focuses on livelihood diversification, infrastructure, and social capital, among other indicators, as factors that mitigate vulnerability and, to a lesser extent, on physical exposure as a driver of vulnerability.

This index may be particularly appropriate for $\mathrm{HKH}$ because it is based on insights distilled from vulnerability research in South Asia, specifically Nepal, India, and Pakistan; thus, it was designed with the regional context in mind. The simple additive framework of VCI makes it easy to use, as demonstrated by its use in Sindh, Pakistan (Ghaus et al. 2015). Additionally, the VCI's structure is quite flexible and can be adapted to specific contexts by simply substituting appropriate variables for those outlined in the original formulations. Finally, as the index was tested, it provided substantial insight into how livelihoods, assets, access to services, and a sense of empowerment all intersect in the overall picture of vulnerability.

Another approach to measuring vulnerability recognized the shortcomings of blanket approaches and proposed the inclusion of livelihood types in the analysis, allowing similar livelihoods to be compared in terms of vulnerability through consideration of specific attributes (Kok et al. 2016). This study's approach recognized that different livelihoods, such as pastoralism and sedentary agriculture, are prone to different vulnerabilities and, thereby, multidimensional indicators should use specific variables for each livelihood type. The authors use this method to develop indicators for smallholder farmers, reasoning that specific socio-ecological dimensions would allow for better transfer of the framework to similar livelihoods. There are two key advantages to this pattern approach. Firstly, it can be applied to assess vulnerability at any scale, including household (Sietz et al. 2012) and regional scales (Sietz 2014). Secondly, the similarities depicted by the vulnerability patterns facilitate the transfer of vulnerability reduction strategies based on the assumption that people living in similar socio-ecological conditions would benefit from similar measures to reduce vulnerability.
Gerlitz et al. (2017) conducted the most comprehensive quantitative study on vulnerability in the $\mathrm{HKH}$, creating a multidimensional livelihood vulnerability index (MLVI) based on the Alkire-Foster method for multidimensional poverty. The MLVI measures can identify not only vulnerable people but also areas of intervention - and if conducted over regular intervals, this index can be used to monitor the success of adaptive policies. The assessment covered 6,100 households in almost 280 settlements in the Upper Indus Basin in Pakistan, the Eastern Brahmaputra Basin in India, and the Koshi Basin in Nepal. Twenty-five indicators were used for each of the three domains of vulnerability, where exposure represents the nature of biophysical threat from climate change, sensitivity constitutes the socioeconomic determinants of differentiated impact, and capacity measures the ability to recover from or adapt to such changes.

Figure 12.9 presents the absolute and relative contribution of vulnerability dimensions by district and sub-basin, indicating that the Upper Indus is the least vulnerable of the three basins. Gerlitz et al. (2017) point out that the theory-based index assigns scores based on normative decisions; thus, the final results are influenced heavily by these decisions. They also acknowledge that applying the same values or weights across large areas may obscure crucial local factors affecting livelihood vulnerability. However, this method can be adapted to local realities by adding or eliminating indicators, making this one of the most comprehensive vulnerability assessments in the region.

It is apparent in Fig. 12.9 that Khotang District of the Koshi Basin in Nepal is the most vulnerable; $96 \%$ of its population is multi-dimensionally vulnerable in terms of $52 \%$ of the 25 vulnerability indicators. Lakhimpur is the most vulnerable in the Eastern Brahmaputra Sub-basin, with 92\% of its population vulnerable; and Chitral District in Pakistan marks the highest vulnerability in the Upper Indus Sub-basin, with $65 \%$ of its population vulnerable (Gerlitz et al. 2017). Figure 12.10 breaks down the composition of the MLVI, showing the absolute and relative contributions of each vulnerability dimension.

By identifying which indicators are the dominant determinants of vulnerability, this analysis is useful in suggesting targeted policy responses. While a lack of adaptive capacity was the greatest absolute contributor to livelihood vulnerability in Lohit and Udayapur (0.17 and 0.16, respectively), Chitral is highest in relative terms, making up $50 \%$ of the MLVI (Gerlitz et al. 2017). To reduce livelihood vulnerability in Chitral, for example, priority may be given to programmes that enhance adaptive capacity or to efforts to improve resources and energy, targeting the specific issues that contribute most to its vulnerability.

The highest absolute contributor to exposure was in Khotang (0.15), whereas exposure marked the highest relative contribution to vulnerability in Hunza-Nagar (38\%) 
Fig. 12.9 Vulnerability in three sub-basins of the HKH: absolute and relative contribution of vulnerability dimensions by district (Gerlitz et al. 2017)

Fig. 12.10 Vulnerability in three sub-basins of the HKH: relative contribution of vulnerability components by district in percentage (Gerlitz et al. 2017)

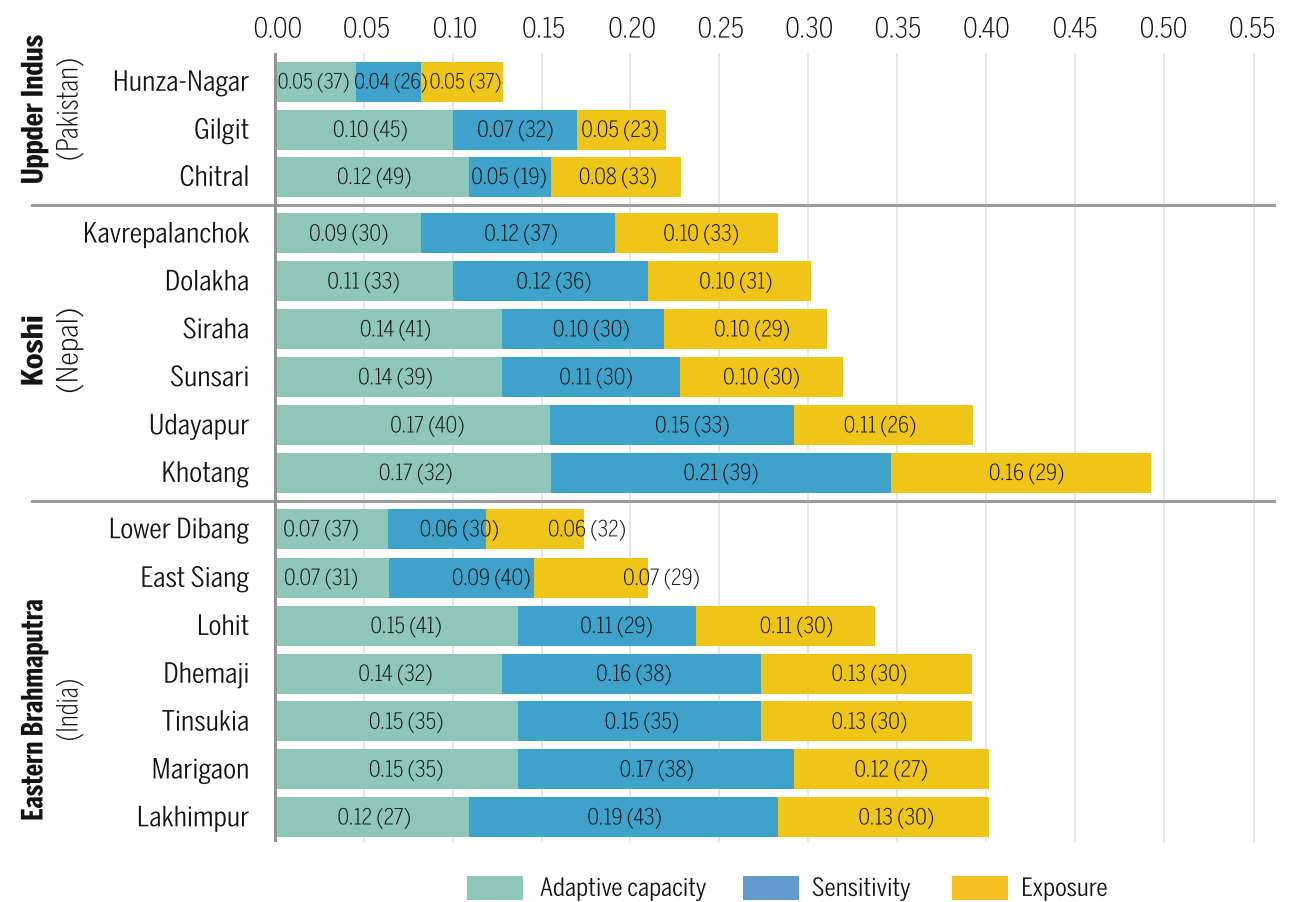

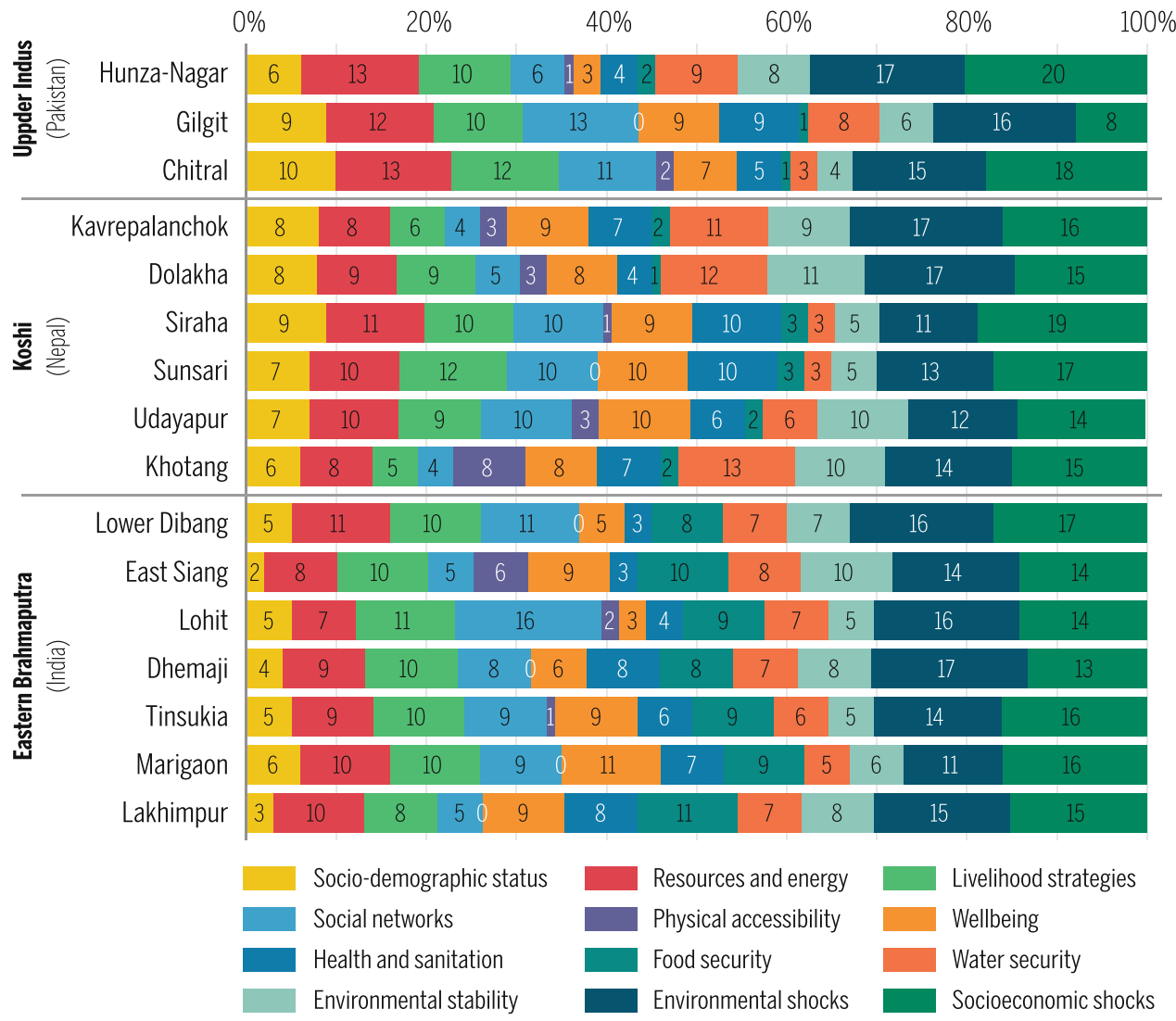

(Gerlitz et al. 2017). Biophysical risk is the biggest contributor to Hunza-Nagar's vulnerability profile, yet this factor alone doesn't amount to high vulnerability overall. In Khotang, on the other hand, biophysical vulnerability is relatively low, yet the combined risks in terms of infrastructure and livelihoods make it the most vulnerable district in the study. By comparing the drivers of vulnerability between Hunza-Nagar and Khotang, it becomes apparent 


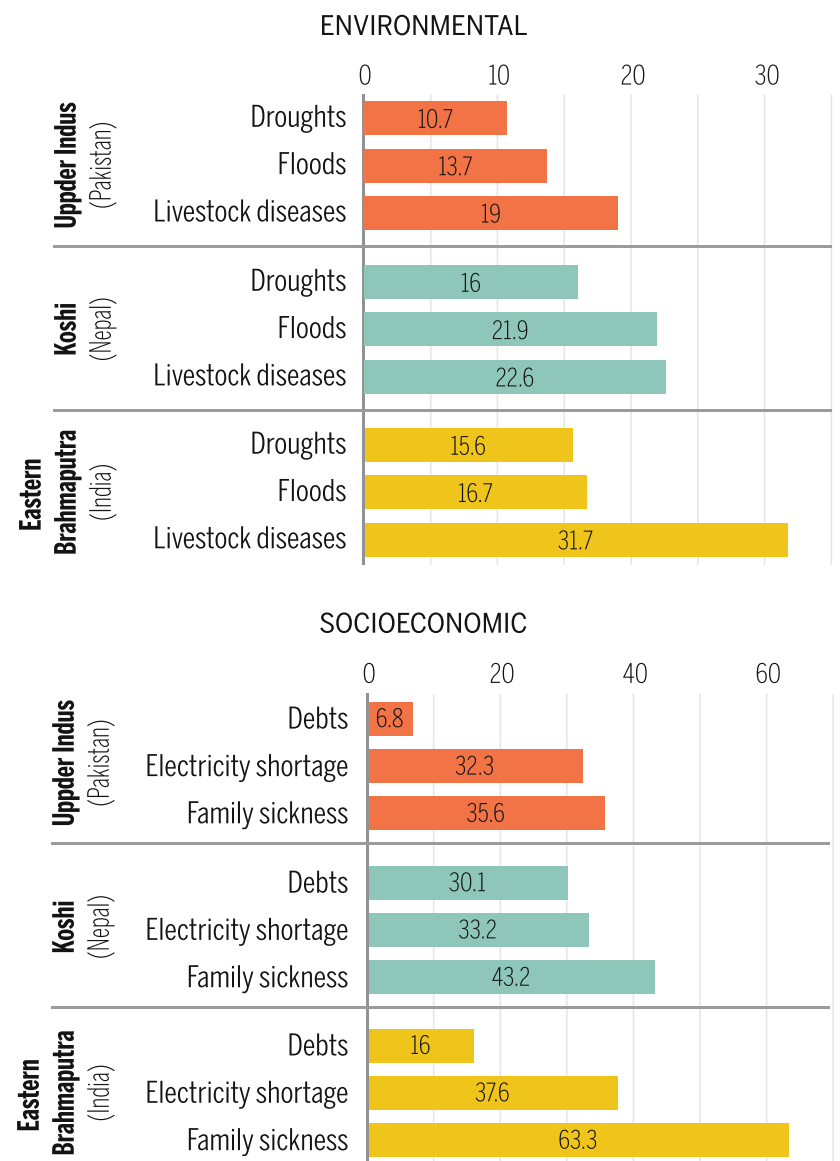

Fig. 12.11 Top three environmental and socioeconomic shocks (Gerlitz et al. 2015b). Notes $\mathrm{N}=6,096 \mathrm{HH}$ (India $=2,647 \mathrm{HH}$, Pakistan $=1,139 \mathrm{HH}$, Nepal $=2,310$ ), weighted analysis, $100 \%$, data: VACA $2011 / 12$

that livelihood and infrastructure are the main drivers of absolute vulnerability.

Exposure to climatic, environmental, and socioeconomic shocks had the most significant impact on vulnerability in each district. Figure 12.11 indicates the top three environmental and socioeconomic shocks to communities, and Fig. 12.12 presents each community's responses to these shocks.

As indicated by these figures, livestock diseases, floods, droughts, erratic rainfall, and irrigation problems caused the most consequential environmental shocks, and communities responded by changing farming practices. In each basin, family illness and electricity shortages caused the most severe socioeconomic shocks, and people within the community often responded by borrowing money.

Such information is extremely useful in suggesting mountain-specific policy options to reduce vulnerability in farming communities, addressing issues within both social and environmental domains to decrease both poverty and vulnerability. Practical measures to support mountain livelihoods include, for example, financial support, decentralized energy production, access to information and research on appropriate farming practices, and timely weather-related data.

Multidimensional vulnerability measures (as described by Alkire and Foster 2011) avoid overly simplistic and overly generalized findings, successfully identifying vulnerable populations and significant areas of intervention, while also allowing the success of adaptive policies to be monitored at regular intervals. The multidimensional vulnerability (and poverty) indices can serve as good baselines for measuring temporal and spatial trends in growth and developmentand for attempting to isolate the climate change factor driving this trajectory. In addition, actual empirical evidence from the field (as opposed to predictive theorizing) would help calibrate VCI models to local realities.

On the other hand, participatory vulnerability and capability analyses are more direct in capturing the problems at hand and thereby constitute a better tool for eliciting policy direction. However, such analyses are place-based-determined by local priorities, landscapes, and livelihoods - and thereby not suitable for comparison, failing any promise of universal application.

\subsubsection{Evidence of the Intersection of Poverty and Vulnerability in the HKH}

This assessment shows that the mountain regions of the HKH have a higher incidence of economic and multidimensional poverty than the plains - and income poverty levels in mountain areas are also higher than in the plains, with the exception of India. Furthermore, there has been less poverty reduction in mountain areas, which has led to increased income inequality between the two regions. Even in India, where several hill states have poverty rates that are lower than the national average, the hill states fare worse than the rest of the country in terms of access to education, healthcare, financial support, infrastructure, and basic amenities. In terms of policy, a significant implication is the need to close the gap in income inequality through more effective poverty-reduction programmes in the mountain areas, including greater investments in education and in development of economic and social infrastructure.

Multidimensional assessment proves to be a better measure of poverty than any single indicator. Livelihoods are intricately - and variously - tied to natural resources and reliant on knowledge of seasonal and climatic change (Elalem and Pal 2015). Therefore, the impacts of climate change on local livelihoods are becoming increasingly severe-and certain livelihood coping strategies are, in turn, impacting climate change. Overall, it is clear that across the $\mathrm{HKH}$ inhabitants are experiencing increased vulnerability to climate change, particularly in terms of livelihood and wellbeing. 
Fig. 12.12 Top three responses to social and environmental shocks (Gerlitz et al. 2015b). Notes Top panel; $\mathrm{N}=5,630 \mathrm{HH}$ (India $=2,490 \mathrm{HH}$,

Pakistan $=1,124 \mathrm{HH}$,

Nepal $=2,016$ ), weighted analysis, $100 \%$, data: VACA 2011/12. Bottom panel:

$\mathrm{N}=5,855 \mathrm{HH}$ (India $=2,571$

$\mathrm{HH}$, Pakistan $=985 \mathrm{HH}$,

Nepal $=2,299)$, weighted analysis, $100 \%$, data: VACA 2011/12
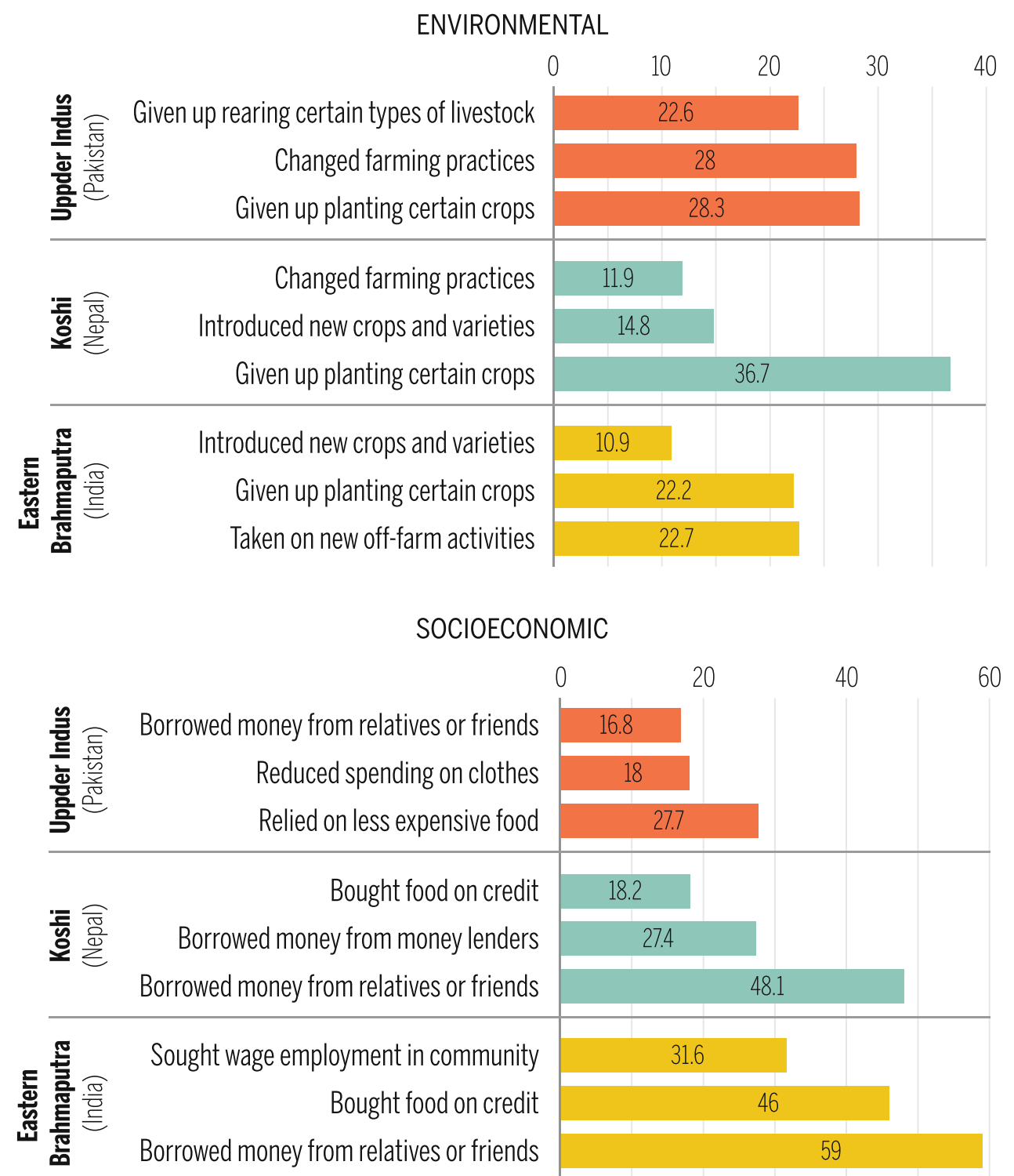

Water, land, and forests are essential resources for HKH residents. Quantitative and qualitative studies indicate that these resources are being affected by climate change and the coping strategies used in response to it. Regionally, studies highlight that while the annual average precipitation has not shifted significantly, there have been more frequent extremes, such as droughts and floods, and rainfall patterns have become less predictable overall (EPASSA 2008; Duncan et al. 2013; Wiltshire 2014). Cloudburst incidents are being reported more frequently in the mountainous regions (Shah 2009), and the amount of precipitation falling as snow has decreased while ablation has increased (Wiltshire 2014).

These changes have made it harder for local people to predict and prepare for the onset of monsoon seasons, making the population more vulnerable to flooding disasters, including glacial lake outburst floods (GLOF) (Gentle et al. 2014). With livelihoods dependent on understanding and predicting these weather patterns, HKH residents are also more vulnerable to disasters caused by drought and landslides.

Research shows that in monsoon-affected regions, just one extreme weather event can account for as much as $10 \%$ of a catchment's yearly water intake, and $50 \%$ of yearly rainfall can occur within a 10-day period (Dahal and Hasegawa 2008; Bookhagen and Burbank 2010). Sediment qualities are also being affected, impacting ecosystems by disrupting irrigation networks, hydropower efforts, and the potable water supply. These extreme weather events not only impact the population's access to ecosystem services but also put residents at risk of physical harm, loss and damage to infrastructure, and food insecurity (see Chaps. 9 and 11). 
With global warming continuing at current rates, precipitation projections for the region become increasingly alarming, necessitating the development of adaptation strategies for the area's huge resident population (Gentle et al. 2014).

Elalem and Pal (2015) conducted an assessment of vulnerability to flooding in the HKH. By looking at the historical record of floods spanning 1951-2013, coupled with demographic and socioeconomic data, they assessed flood disaster locations and the resulting economic and human impacts. The authors produced vulnerability maps marking the what, where, and when of the disaster impacts across the HKH. In terms of time, the results indicated a clear trend across the whole region: There were more frequent and more intense disasters throughout 2001-13.

Elalem and Pal (2015) also highlighted economic damages associated with flood disasters. In light of Pakistan's 2010 mega floods, it is not surprising that the authors found that Pakistan experienced the greatest economic damages per disaster, followed by China and India. However, it is notable that the HKH countries with lower GDP (Nepal and Afghanistan, along with Pakistan) were more vulnerable to economic loss throughout the full period of assessment than their wealthier counterparts. This means that poorer countries are less able to respond to extreme events and disasters, indicating that poverty and vulnerability are interlinked. This also suggests a regional strategy of reducing vulnerability by integrating disaster resilience into broader poverty-reduction strategies.

Desertification, in particular, is a concern for $\mathrm{HKH}$ populations residing in India and Pakistan. (Ning et al. 2013) concurs that desertification, degradation, and soil erosion are being exacerbated by climate change in the HKH's high-altitude rangelands. Desertification is affecting landscape productivity in many sites, including the Manasarovar catchment in China, various sites in Nepal, and in Sindh, Gilgit-Baltistan, and Balochistan in Pakistan.

In Nepal, the National Action Programme on Land Degradation and Desertification estimates that around 3.3 million hectares (28.2\% of the country's total land) are experiencing the process of desertification (Tiwari and Joshi 2012; GoN 2016). In terms of degradation, $70 \%$ of the total degraded land is in the forests and the rangelands. Tiwari and Joshi (2012) contend that the drivers of this desertification and degradation are the combination of climate change, infrastructure development, and the coping strategies of populations in poverty, including land-use patterns, settlement, infrastructure development for fuelwood and timber, tree cutting and forest clearing for agriculture, mass wasting, flooding and erosion, and rockslides. Despite these significant figures in Nepal, EPASSA (2008) estimates that the impacts of desertification will be even more severe for Pakistan and India.
Authors highlight several broad linkages between poverty and vulnerability across the HKH, which are exacerbated by climate change impacts. Some of the most consistently reported include:

- Lack of economic diversification resulting in sustained dependence on a degrading and increasingly fragile ecosystem for consumption and livelihood (Suich et al. 2015)

- High dependency of downstream communities on upstream ecosystem services for dry-season water for irrigation, hydropower, drinking water, and soil fertility and nutrients - especially in South Asian HKH countries (Rasul 2014). Moreover, poorer people who depend on mountain ecosystems for survival are not incentivized to conserve resources (Rasul 2014).

- Continued overuse of groundwater-irrigated agriculture, which provides food security for approximately 60-80\% of the population, but degrades the groundwater resources needed for other livelihood uses (Shah 2009).

- Growing demand for timber and fuelwood to support industry and livelihoods that has led to heavy degradation of forest resources, upon which poor communities depend (Haigh 1990; Rasul 2014).

\subsubsection{Knowledge Gaps and Recommendations}

There are some key knowledge gaps in the literature on vulnerability in the HKH that should be explored and illuminated with new empirical research. The most striking gap is in the limited geographical focus of the evidence base. The majority of research focuses on Nepal and India, and there is a need for greater investigation across Pakistan, Afghanistan, Bhutan, Myanmar, Bangladesh, and China. Climate and environment data also needs to be improved and expanded to encompass a comprehensive understanding of the HKH. Data collection is often sparse in the rugged, high-elevation areas of the $\mathrm{HKH}$, which poses a challenge for accurate climate modeling and prediction of climate change effects for such areas. Furthermore, there are also significant gaps in scientific knowledge of climate change, including the effects of black carbon and melting permafrost and the impact of transient groundwater storage on water regimes.

Another key gap in existing literature is in understanding the differentiated impacts of climate change on poverty and vulnerability across different geographical zones within the HKH. Generally, the literature assumes that the nexus between climate change, poverty, and vulnerability can be understood through regional research - but this is debatable, as the studies reviewed highlight highly differentiated 
impacts depending on local geography, socioeconomic structure, and experienced impacts. Most poverty reduction programmes do not take mountain specificities into consideration; thereby these efforts may actually increase climate risk and fragility in the $\mathrm{HKH}$ - or, at best, prove to be less effective in the mountains than in the lowlands. It may be useful to categorize different geographical zones across the $\mathrm{HKH}$ according to different factors, and then understand how such differentiated spaces and populations are impacted by climate change.

Participatory research is also needed to understand the intersectional impacts of climate change on poverty and vulnerability. The literature highlights the significance of intersectional categories - especially gender-in accessing livelihood adaptation strategies (Shields 2008). As discussed above, the intersection of gender and economic marginality leads to increased vulnerability and reduced access to sustainable adaptation strategies. Targeted investments informed by this understanding would increase the effectiveness of development efforts and help reduce vulnerability.

Hewitt and Mehta (2012) argued that marginalization in mountain areas is due to subordination of the specific regional socioeconomic planning by larger strategic planning at the state level. In simple terms, mountain-specific socioeconomic planning does not work in service of other and larger geographies-especially not the plains. Therefore, fewer socioeconomic development gains are made in mountain areas. Such trends in mountain-area marginalization have been observed in poverty-reduction strategies as well.

Evidence in this assessment suggests that reduction of both poverty and vulnerability can be achieved through coordinated interventions that are contextualized, intersectional, and mountain specific. Multidimensional poverty measures - which assess multiple deprivations in education, health, and standard of livingvare appropriate for poverty assessment in mountain areas. Since there is an acute shortage of mountain-specific poverty data, an important policy implication is that governments and development partners should allocate more resources to build a comprehensive database using longitudinal surveys at the regional and national levels. Such a database would strengthen, complement, and substantiate the macro-level findings, which are based on the nationally representative datasets. Further assessment could be used to identify and document pockets of poverty and vulnerable communities throughout all HKH countries using a long-term monitoring system.

Where the government cannot provide adequate social protection, investment in social mobilization can strengthen traditional social networks to effectively reduce vulnerability, as has been demonstrated in some areas of Pakistan (Khan 2014). Additionally, income inequality in mountain regions can be addressed through mountain-specific poverty-reduction programmes, including larger per capita investment in education and the development of economic and social infrastructure.

Local promotion of eco-tourism (such as the home-stay model) has significant potential for promoting mountain economies, while supporting women and sustainable, resilient development. By contrast, large direct investment in eco-tourism may increase climate vulnerability by exerting pressures on the environment, though more research needs to be done on different models of tourism and their risks and opportunities across the HKH.

In agriculture, traditional irrigation practices can also be further investigated to identify both risks and opportunities. The application of modern technologies and techniques might allow traditional practice to become sustainable and resilient. Reforesting lands that have become suboptimal for agriculture can encourage groundwater recharge and provide alternate livelihoods based on ecosystem services, such as fibre production and tourism (Chaudhary and Aryal 2009).

Regional and national strategies have had differential impacts on mountain poverty and may even increase vulnerability of mountain livelihoods. Promotion of high-value crops, for example, may be useful by increasing income, but over-promotion will reduce the diversity of income sources, making the endeavour highly susceptible to a covariant risk of large-scale failure due to an unpredicted pest or a shift in rain and temperature patterns.

\section{References}

Adhikari, J. (2014). Agriculture adaptation practices in South Asia: Case of Nepal. Working Paper No. 01(iii)/14. South Asia Watch on Trade, Economics and Environment (SAWTEE).

Adhikari, L., Hussain, A., \& Rasul, G. (2017). Tapping the potential of neglected and underutilized food crops for sustainable nutrition security in the mountains of Pakistan and Nepal. Sustainability, 9, 291.

Adhikari, J., \& Hobley, M. (2012). Everyone is leaving-Who will sow our fields?: Impact of migration to Gulf and Malasiya in Khotang district, Nepal. Kathmandu: NIDS and SDC.

Asian Development Bank, ADB. (2012). Bangladesh: Chittagong hill tracts rural development project. Manila: ADB. https://www.adb. org/sites/default/files/evaluation-document/36065/files/pvr-222.pdf.

Anand, S., \& Sen, A. (1998). The income component of the human development index. (mimeo). New York: Human Development Report Office, UNDP.

Alkire, S., \& Santos, M. E. (2010). Acute multidimensional poverty: A new index for developing countries. OPHI Working Papers 38, University of Oxford.

Alkire, S., Foster, J. E., Seth, S., Santos, M. E., Roche, J., \& Ballón, P. (2015). Multidimensional poverty measurement and analysis. Oxford University Press.

Alkire, S., \& Seth, S. (2013). Multidimensional poverty reduction in India 1999-2006: Slower progress for the poorest groups. Oxford Poverty \& Human Development Initiative.

Alkire, S., \& Foster, J. (2011). Understandings and misunderstandings of multidimensional poverty measurement, 9(2), 289-314. 
Adger, W. N., Huq, S., Brown, K., Conway, D., \& Hulme, M. (2003). Adaptation to climate change in the developing world. Progress in Development Studies, 3(3), 179-195.

Adger, N. (2006). Vulnerability. Global Environment Change, 16(3), 268-281.

Adger, N., \& Kelly, M. (1999). Social vulnerability to climate change and the architecture of entitlements. Mitigation and Adaptation Strategies for Global Change, 4, 253.

Altieri, M. A. (1999). Applying agroecology to enhance the productivity of peasant framing systems in Latin America. Environment, Development and Sustainability 1, 197-217. Kluwer Academic Publisher: The Netherlands.

Ali, J. (2007). Livestock sector development and implications for rural poverty alleviation in India. Livestock Research for Rural Development 19(2).

Apetrei, C. (2012). Food security and millet cultivation in the Kumaon region of Uttarakhand. Research Report for Gene Campaign.

APHCA and ILRI. (2006). Goats-Undervalued assets in ASIA. In Proceedings of the APHCHA-ILRI Regional Workshops on Goat Production System and Markets.

Azhar-Hewitt, F. (2011). The other side of silence: The lives of women in the Karakoram mountains. Bloomington: iUniverse.

Ali, I.., \& Pernia, E. M. (2003). ERD policy brief series: Economics and research department infrastructure and poverty reductionWhat is the connection (no. 13).

Bhagmal. (2007). Neglected and underutilized genetic resources for sustainable agriculture. Indian Journal of Plant Genetic Resources, 22(1):1-16.

Bharadwaj, B. (2012). Roles of cooperatives in poverty reduction: A case of Nepal. Administration and Management Review, 24.

Banerjee, S., Gerlitz, J. Y., \& Hoermann, B. (2011). Labour migration as a response strategy to water hazards in the Hindu Kush Himalayas. Kathmandu: ICIMOD.

Banerjee, S., Sijapati, B., Poudel, M., Bisht, S., \& Kniveton, D. (2016). Role of remittances in building farm assets in the flood affected households in Koshi sub-basin in Nepal. Springer International Publishing Switzerland 2016. In A. Milan et al. (Eds.), Migration, risk management and climate change: Evidence and policy responses, global migration issues (vol. 6). https://doi.org/10. 1007/978-3-319-42922-9_2.

Berhanu, W., Colman, D., \& Fayissa, B. (2007). Diversification and livelihood sustainability in a semi-arid environment: A case study from Southern Ethiopia. The Journal of Development Studies, 43 , 871-889. https://doi.org/10.1080/00220380701384554.

Bird, R. B., Bird, D. W., Smith, E. A., \& Kushnick, G. C. (2002). Risk and reciprocity in Meriam food sharing. Evolution and Human Behavior, 23, 297-321.

Blaikie, P. M., \& Sadeque, Z. (2000). Policy in high places. Kathmandu: International Centre for Integrated Mountain Development.

Bolin, B. (2007). Race, class, ethnicity, and disaster vulnerability. In Handbook of Disaster Research (pp. 113-129).

Bookhagen, B., \& Burbank, D. W. (2010). Toward a complete Himalayan hydrological budget: Spatiotemporal distribution of snowmelt and rainfall and their impact on river discharge. Journal of Geophysical Research. https://doi.org/10.1029/2009jf001426.

Brithal, P. S., \& Taneja; V. K. (2006). Livestock sector in India: Opportunities and challenges for the small holders. In Workshop on small holder livestock production in India: Opportunities and challenges, New Delhi.

Central Bureau of Statistics (CBS). (2011). Poverty in Nepal 2010-11. http://cbs.gov.np/image/data/Surveys/poverty\%20in\%20Nepal\% 202010-11/CBS\%20view\%20on\%20poverty\%20in\%20Nepal.pdf.

Central Bureau of Statistics (CBS). (2014). Population monograph of Nepal: Volume I (population dynamics). National Planning Commission Secretariat, Government of Nepal.
Chambers, R.., \& Conway, G. (1992). Sustainable rural livelihoods: Practical concepts for the 21st Century. Discussion Paper 296. Sussex: IDS

Chand, R., Raju, S. S., \& Pandey, L. M. (2008). Progress and potential of horticulture in India. Paper prepared for the 68th annual conference of the Indian society of agricultural economics, 28-30 November 2008, Andhra University, Visakhapatnam, India.

Chaudhary, P., \& Aryal, K. P. (2009). Global warming in Nepal: Challenges and policy imperatives. Journal of Forest and Livelihood, $8(9)$

Chen, X. (2011). Agricultural situation and rural policy in today's China. http://www.snzg.cn/article/2011/1117/article_26276.html.

Cutter, S. (1996). Vulnerability to environmental hazards. Progress in Human Geography, 20, 529-539.

Dahal, R. K., \& Hasegawa, S. (2008). Representative rainfall thresholds for landslides in the Nepal Himalaya. Geomorphology, 100(3-4), 429-443. https://doi.org/10.1016/j.geomorph.2008.01.014.

Dame, J., \& Nusser, M. (2011). Food security in high mountain regions: Agricultural production and the impact of food subsidies in Ladakh, Northern India (Springer), 3(2), 179-194.

Dasgupta, P., Morton, J. M., et al. (2014). Rural areas. In C. B. Field, \& V. R. Barrros et al. (Eds.), Climate change 2014: Impacts, adaptation and vulnerability. Report of the working group II, Intergorvernmental Panel on Climate Change. Cambridge University Press: Cambridge.

Dazé, A., Ambrose, K., \& Ehrhart, C. (2009). Climate vulnerability and capacity analysis (Handbook). Londong: CARE International.

Delgado, C. (2005). Rising demand for milk and meat in developing countries: Implications for grasslands-based livestock production. In Grassland: A global resource (pp. 29-39). The Netherlands: Wageningen Academic Publishers.

Desakota Team. (2008). Re-imagining the rural-urban continuum: Understanding the role ecosystem services play in the livelihoods of the poor in Desakota regions undergoing rapid change. Institute for Social and Environmental Transition-Nepal (ISET-Nepal).

DFID. (1999). Sustainable livelihoods guidance sheets. London, UK: Department for International Development.

de Haan, A. (1999). Livelihoods and poverty: The role of migration-A critical review of the migration literature. The Journal of Development Studies, 36(2).

Dorji, W. (2011). Opportunities and constraints to community forests for local income generation and livelihoods: A case study of four community forest in Bumthang District, Bhutan. MS thesis, University of Montana, Missoula.

Duncan, J. M. A., Biggs, E. M., Dash, J., \& Atkinson, P. M. (2013). Spatio-temporal trends in precipitation and their implications for water resources management in climate-sensitive Nepal. Applied Geography, 43, 138-146.

Eakin, H., \& Bojorquez-Tapia, L. A. (2008). Insights into the composition of household vulnerability from multi-criteria decision analysis. Global Environmental Change, 18, 112-127.

Ediger, L., \& Huafang, C. (2006). Upland China in transition: The impacts of afforestation on landscape patterns and livelihoods. Mountain Research and Development, 26 (3).

Elalem, S., \& Pal, I. (2015). Mapping the vulnerability hotspots over Hindu-Kush Himalaya region to flooding disasters. Weather and Climate Extremes, 8, 46-58.

Escobal, J., \& Torero, M. (2005). Adverse geography and differences in welfare in Peru. In R. Kanbur \& A. J. Venables (Eds.), Spatial inequality and development. Oxford University Press. January.

EPASSA. (2008). Ecosystem services and poverty alleviation study in South Asia. A situation analysis for India and the Hindu Kush Himalayan region (Annexure 3).

Eyzaguirre, P., Padulosi, S., \& Hodgkin, T. (1999). IPGRI's strategy for neglected and underutilized species and the human dimension of 
agrobiodiversity. In S. Padulosi (Ed.), Priority setting for underutilized and neglected plant species of the mediterranean region. Report of the IPGRI Conference, 9-11 February 1998. Aleppo, Syria: ICARDA; Rome, Italy: IPGRI.

FAO. (2010). Integration of gender in agriculture. Nepal.

FAO. (2017). Future smart food. Unlocking hidden treasures in Asia and the Pacific. Retrieved October 2017, from http://www.fao.org/ 3/a-i7717e.pdf.

Ferguson, J. A. (2012). Generating sustainable livelihoods; the role of co-operatives. Cooperatives as transformative agents in building sustainable livelihoods and reducing poverty. In Harnessing the co-operative advantage to build a better world.

Füssel, H. M., \& Klein, R. J. T. (2006). Climate change vulnerability assessments: An evolution of conceptual thinking. Climatic Change, 75, 301. https://doi.org/10.1007/s10584-006-0329-3.

Frison, E. A., Smith, I. F., Johns, T., Cherfas, J., \& Eyzaguirre, P. B. (2006). Agricultural biodiversity, nutrition, and health: making a difference to hunger and nutrition in the developing world. Food and Nutrition Bulletin, 27(2), 167-179.

Ganesh, A., \& Madhavi, C. (2007). Impact of tourism on Indian economy-A snapshot. Journal of Contemporary Research in Management, 1(1), 2.

Gentle, P., Thwaites, R., Race, D., \& Alexander, K. (2014). Differential impacts of climate change on communities in the middle hills region of Nepal. Natural Hazards, 74(2), 815-836.

Gerber, P., Mooney, H. A., Dijkman, J., Tarawali, S., \& Haan, C. (2010). Livestock in changing landscape: Experiences and regional perspectives (vol. 2). Island Press.

Gerlitz, J. Y., Macchi, M., Brooks, N., Pandey, R., Banerjee, S., \& Jha, S. K. (2017). The multidimensional livelihood vulnerability indexAn instrument to measure livelihood vulnerability to change in the Hindu Kush Himalayas. Climate and Development, 9(2), 124-140.

Gerlitz, J. Y., Apablaza, M., Hoermann, B., Hunzai, K., \& Bennett, L. (2015a). A multidimensional poverty measure for the Hindu Kush-Himalayas, applied to selected districts in Nepal. Mountain Research and Development, 35(3), 278-288.

Gerlitz, J. Y., Banerjee, S., Brooks, N., Hunzai, K., \& Macchi, M. (2015b). An approach to measure vulnerability and adaptation to climate change in the Hindu Kush Himalayas. In Handbook of Climate Change Adaptation (pp. 151-176).

Gerlitz, J. Y., Banerjee, S., Hoermann, B., Hunzai, K., Macchi, M., \& Tuladhar, S. (2014). Poverty and vulnerability assessment: A survey instrument for the Hindu Kush Himalayas. Kathmandu: International Centre for Integrated Mountain Development.

Gerlitz, J. Y., Hunzai, K., \& Hoermann, B. (2012). Mountain poverty in the Hindu-Kush Himalayas. Canadian Journal of Development Studies, 33, 250-265.

Ghaus, K., Manzoor, H., Memon, M. A. I., Nadeem, A., Naveed, A., \& Tabinda, A. (2015). Gender and social vulnerability to climate change: A study of disaster prone areas in Sindh, Pakistan. Social Policy and Development Centre (SPDC): Karachi, Pakistan. Retrieved 19 March, 2017, from http://www.spdc.org.pk/ Publication_detail.aspx?sysID=786.

Gioli, G., Khan, T., Bisht, S., \& Scheffran, J. (2014a). Migration as an adaptation strategy and its gendered implications: A case study from the Upper Indus Basin. Special issue "Gender and sustainable development in mountains: Innovative transformations, tenacious resistances". Mountain Research and Development, 34(3), 255-265.

Gioli, G., Khan, T., \& Scheffran, J. (2014b). Climatic and environmental change in the Karakoram: Making sense of community perceptions and adaptation strategies. Regional Environmental Change, 14, 1151-1162.

Gioli, G, Maharjan, A., \& Gurung, M. (2017) Neither heroines nor victims: Women migrant workers and changing family and community relations in Nepal. New York: UN WOMEN Working Paper Series.

Goodall, S. K. (2004). Rural-to-urban migration and urbanization in Leh, Ladakh: A case study of three nomadic pastoral communities. Mountain Research and Development, 24, 220-227.

GoN. (2016). Nepal: Zero hunger challenge national action plan (2016-2025). Kathmandu. http://www.npc.gov.np/images/category/ ZHC_NAP_(2016_-_2025).pdf.

GoP. (2006). Agricultural census organization, statistics division. Government of Pakistan, Gulberg, Lahore.

Gurung, K., Tulachan, P. M., \& Gauchan, D. (2005). Gender and social dynamica in livestock management: A case study from three ecological zones in Nepal. Gender Component, LPP Project. CEMORD and NARC.

Halvorson, S. J. (2002). Environmental health risks and gender in the Karakoram himalaya, Northern Pakistan. Geographical Review. https://doi.org/10.1111/j.1931-0846.2002.tb00007.x.

Haigh, P. M. (1990). Effect of herbage water-soluble carbohydrate content and weather conditions at ensilage on the fermentation of grass silages made on commercial farms. Grass \& Forage Science, $45,263-271$.

Hewitt, K., \& Mehta, M. (2012). Rethinking risk and disasters in mountain areas. Journal of Alpine Research (Online). https://doi. org/10.4000/rga.1653.

Hannum, E., \& Wang, M. (2012). China: A case study in rapid poverty reduction. In H. Gillette \& $\mathrm{P}$. Harry (Eds.), In indigenous people, poverty, and development. Cambridge: Cambridge University Press.

Herbers, H. (1998). Work and nutrition in High Asia. Theoretical framework, methods and main results of a comprehensive study on the production-reproduction-system in northern Pakistan. EBHR, $14,18-30$.

Herrero, M., Thornton, P. K., Notenbaert, A. M., Wood, S., Msangi, S., Freeman, H. A., et al. (2010). Smart investments in sustainable food production: Revisiting mixed crop-livestock systems. Science, 327, $822-825$.

Hoermann, B., Banerjee, S., \& Kollmair, M. (2010). Labour migration for development in the Western Hindu Kush-Himalayas-Understanding a livelihood strategy in the context of socioeconomic and environmental change. Kathmandu: International Centre for Integrated Mountain Development.

Hunzai, K., Gerlitz, J. Y., \& Hoermann, B. (2011). Understanding mountain poverty in the Hindu Kush-Himalayas: regional report for Afghanistan, Bangladesh, Bhutan, China, India, Myanmar, Nepal, and Pakistan. Kathmandu: ICIMOD.

ICIMOD and GRID Arendal. (2014). The last straw: Food security in the Hindu Kush Himalayas and the additional burden of climate change. Kathmandu: ICIMOD.

IFAD. (2013). Sending money home to Asia. ISBN 978-92-9072401-8.

IFAD. (2002). Regional strategy paper-Asia and the Pacific. IFAD, March 2002. https://www.ifad.org/documents/10180/3b116bbd70d6-4219-e4c8b6011866.

IOM. (2005). World migration 2005: Costs and benefits of international migration. Geneva: International Organization for Migration.

IPCC. (2012). In C. B. Field, V. Barros, \& T. F. Stocker, et al. (Eds.), Managing the risks of extreme events and disasters to advance climate change adaptation. Special report of the Intergovernmental Panel on Climate Change. Cambridge and New York: Cambridge University Press.

Isaac, M. (2012). Community-based ecotourism and livelihood enhancement in Sirigu, Ghana. International Journal of Humanities and Social Science, 2(18).

Jarvis, D., Sthapit, B., Raj Bhatta, M., \& Sthapit, S. (2014). Integrating traditional crop genetic diversity for mountain food security. Biodiversity International, 2p. 
Jodha, N. S. (1990a). A framework for integrated mountain development. Mountain Farming Systems Discussion Paper No. 1. Kathmandu: International Centre for Integrated Mountain Development (ICIMOD)

Jodha, N. S. (1990b). Mountain agriculture: Search for sustainability. Journal of Farming System Research Extension, 1(1).

Jodha, N. S. (1992). Mountain perspective and sustainability: A framework for development strategies. In: N. S. Jodha, M. Banskota, \& T. Partap (Eds.), Sustainable mountain agriculture, volume 1: Perspectives and issues. New Delhi: Oxford and IBH.

Jodha, N. S. (1997). Mountain agriculture. In B. Messerli \& J. D. Ives (Eds.), Mountains of the world: A global priority. New York/Carnforth Lancashire: The Parthenon Publishing Group.

Kanbur, R., \& Venables, A. J. (2005a). Spatial inequality and development. Oxford University Press.

Kanbur, R., \& Venables, A. J. (2005b). Rising spatial disparities and development. UNU-WIDER Policy Brief, United Nations University, November.

Karki, M., Sharma, S., Mahat, T. J., Tuladhar, A., \& Aksha, S. (2012). Sustainable mountain development 1992, 2012 and beyond-Rio +20 assessment report for the Hindu Kush Himalayan Region. International Centre for Integrated Mountain Development.

Karki, M. (2012). The effects of climate change in the Himalayan regions (Jalabayu paribartanle himali kshetrama pareko prabhav). Hamro Sampada, 12(2), 97-98.

Kaspar, H. (2005). I am the household head now! Gender aspects of out-migration for labour in Nepal. Kathmandu: NIDS.

Katwal, T. B. (n.d.) Multiple cropping in Bhutanese agriculture-present status and opportunities. Paper presented during the "Regional Consultative Meeting on Popularizing Multiple Cropping Innovations as a Means to raise Productivity and Farm Income in SAARC Countries" 31st October-1st November, Peradeniya, Kandy, Srilanka.

Khan, U. F. M., \& Ashfaq, F. (2010). Meat production potential of small ruminants under the arid and semi-arid conditions of Pakistan. Agricultural and Marine Sciences, 15, 33-39.

Khan, F. (2014). Adaptation vs. development: Basic services for building resilience. Development in Practice, 24(4), 559-578. https://doi.org/10.1080/09614524.2014.908823.

Khattri, M. B. (2012). Climate change, millet and ritual relationship with the magars of Argal, Baglung, Nepal. Dhaulagiri Journal of Sociology and Anthropology, 6.

Kok, M., Lüdeke, M., \& Lucas, P. (2016). A new method for analysing socio-ecological patterns of vulnerability. Regional Environmental Change, 16, 229.

Kreutzmann, H. (2006). Introduction. In H. Kreutzmann (Ed.), Karakoram in transition, culture, development, and ecology in the Hunza Valley (pp. 1-4). Oxford/Karachi: Oxford University Press.

Kruk, E. (2010). Two decades of mountain tourism in ICIMOD 1989_ 2010. ICIMOD

Le De, L., Gaillard, G. C., \& Friesen, W. (2013). Remittances and disaster: A review. International Journal of Disaster Risk Reduction, 4, 34-43.

Macchi, M. (2011). Framework for community-based climate vulnerability and capacity assessment in mountain areas. Kathmandu, Nepal: International Centre for Integrated Mountain Development.

Macchi, M., \& Gurung. (2015). Community perceptions and responses to climate variability and change in the Himalayas. Climate and Development. 7, 5 .

Maharjan, A., Bauer, S., \& Knerr, B. (2013). Migration for labor and its impacts on farm production in Nepal. Centre for the Study of Labor and Mobility, Working Paper IV.

Mamgain, R. P. (2004). Employment, migration and livelihoods in the hill economy of Uttarakhand. Ph. D. Thesis, Jawaharlal Nehru University, New Delhi.
McCarthy, J., \& D, Mustafa. (2014). Despite the best intentions? Experiences with water resource management in northern Afghanistan. In E. Weinthal, J. Troell, \& M. Nakayama (Eds.), Water and post-conflict peacebuilding. London: Earthscan.

Ministry of National Planning and Economic Development, UNICEF, UNDP \& SIDA. (2011). (2009-2010): Poverty Profile.

Mitra, S. (2014). Synergies among monetary, multidimensional and subjective poverty: Evidence from Nepal. Social Indicators Research. 12 December 2014. Retrieved 27 May, 2015, from http://dx.doi.org/10.1007/s11205-014-0831-3.

Mohanty, S. K., Rasul, G., Mahapatra, B., Choudhury, D., Tuladhar, S., \& Holmgren, E. V. (2018). Multidimensional poverty in mountainous regions: Shan and Chin in Myanmar. Social Indicators Research, 138, 23-44.

Monsutti, A. (2008). Afghan Migratory Strategies and the Three Solutions to the Refugee Problem. Refugee Survey Quarterly, 27(1), 58-73.

Morchain, D., Prati, G., Kelsey, F., \& Ravon, L. (2015). What if gender became an essential, standard element of vulnerability assessments? Gender \& Development, 23(3).

Mustafa, D., \& Qazi, U. (2007). Transition from Karez to Tubewell irrigation: Development, modernization and social capital in Balochistan Pakistan. World Development, 35(10), 1796-1813.

Mustafa, D., Ahmed, S., Saroch, E., \& Bell, H. (2011). Pinning down vulnerability: From narratives to numbers. Disasters, 35, 62-86.

Mwangi, S., \& Kimathi, M. (2006). African leafy vegetables evolves from underutilized species to commercial cash crops. In Research workshop on collective action and market access for smallholders, 2-5 October 2006, Cali, Colombia (pp. 1-19).

Nightingale, A. J. (2011). Bounding difference: The embodied production of gender, caste and space. Geoforum, 42(2), 15-162.

Ning, W., Rawat, G. S., Joshi, S., Ismail, M., \& Sharma, E. (2013). High-altitude rangelands and their interfaces in the Hindu Kush Himalayas. Kathmandu: International Centre for Integrated Mountain Development.

Nepal, S. K., \& Chipeniuk, R. (2005). Mountain tourism-Toward a conceptual framework. Tourism Geographies, 7, 313-333.

Odell, M. J., \& Lama, W. B. (1998). Tea house trekking in Nepal: The case for environmentally friendly indigenous tourism. In P. East, K. Luger, \& K. Inmann (Eds.), Sustain ability in mountain tourism: Perspectives for the Himalayan countries (pp. 191-206). Innsbruck-Vienna: Oeko Himal Publication.

Oxford Poverty and Human Development Initiative (OPHI). (2016). Multidimensional poverty index in Pakistan. Oxford: OPHI. http:// www.ophi.org.uk/ophi_stories/pakistan-launches-mpi/.

Padulosi, S., Bergamini, N., \& Lawrence, T. (Eds.). (2011). On farm conservation of neglected and underutilized species: Status, trends and novel approaches to cope with climate change. In Proceedings of an international conference, Frankfurt, 14-16 June 2011. Rome: Bioversity International.

Pandey, R., \& Jha, S. K. (2011). Climate vulnerability index-Measure of climate change vulnerability to communities: A case of rural Lower Himalaya, India. Mitigation and Adaptation Strategies for Global Change, 17(5).

Pandey, P. R., Pandey, H., \& Nakagawa, M. (2009). Assessment of rice and maize based cropping systems for rural livelihood improvement in Nepal. Journal of Agriculture and Environment, 10, 57-64.

Papola, T. S. (2002). Poverty in mountain areas of the Hindu Kush Himalayas: Some basic issues in measurement, diagnosis and alleviation, talking points 2/02. Kathmandu: ICIMOD.

Pelling, M., \& High, C. (2005). Understanding adaptation: What can social capital offer assessments of adaptive capacity? Global Environmental Change, 15(4), 308-319.

Rasul, G. (2014). Food, water, and energy security in South Asia: A nexus perspective from the Hindu Kush Himalayas. Environmental Science \& Policy, 26(2), 174-180. 
Regmi, B. R., Morcrette, A., Paudyal, A., Bastakoti, R., \& Pradhan, S. (2010). Participatory tools and techniques for assessing climate change impacts and exploring adaptation options. A community based tool kit for practitioners livelihoods and forestry programme. Kathmandu, Nepal: UKAID, Livelihoods and Forestry Programme (LFP).

Roche, J. M., Santos, M. E. (2013). In search of a multidimensional poverty index for Latin America. In Presented at 10th Arnoldshain Seminar, 29 June-2 July, Gottingen, Alemania; 2013ECINEQ Meeting, 2-24 July 2013, Bari, Italy.

Salick, J., Yongpin, Y., \& Amend, A. (2005). Tibetan land use and change near Khawa Karpo, Eastern Himalayas. Economic Botany, 59, 312-325.

Santos, M. E. (2013). Tracking poverty reduction in Bhutan: Income deprivation alongside deprivation in other sources of happiness. Social Indicators Research, 112(2), 259-290.

Saxena, N. (2016). Socio-economic development in the north-eastern states of India. New Delhi (unpublished): UNDP.

Schrieder, G., \& Knerr, B. (2000). Labour migration as a social security mechanism for smallholder households in Sub-Saharan Africa: The case of Cameroon. Oxford Development Studies, 28, 223-236. https://doi.org/10.1080/713688309.

Sen, A. (1992). Inequality reexamined. Oxford: Clarendon Press.

Sen, A. (1999). Development as freedom. Oxford: Oxford University Press.

Shah, T. (2009). Climate change and groundwater: India's opportunities for mitigation and adaptation. Environmental Research Letters, 4, 035005 .

Sharma, P. (Ed.). (2000). Tourism as development: Case studies from the Himalaya. Innsbruck, Wien, Munchen: Himal Books and STUDIENVerlag.

Shields, S. A. (2008). Gender: An intersectionality perspective. Sex Roles, 59, 301-311.

Sietz, D., Mamani Choque, S. E., \& Lüdeke, M. K. B. (2012). Typical patterns of smallholder vulnerability to weather extremes with regard to food security in the Peruvian Altiplano. Regional Environmental Change, 12(3), 489-505.

Sietz, D. (2014). Regionalisation of global insights into dryland vulnerability: Better reflecting smallholders' vulnerability in Northeast Brazil. Global Environmental Change, 25(1), 173-185.

Singh, S. P., Khadka, I. B., Karky, B. S., \& Sharma, E. (2011). Climate change in the Hindu Kush-Himalayas the state of current knowledge. Kathmandu, Nepal: International Centre for Integrated Mountain Development.

Singh, P., \& Raghuvanshi, R. S. (2012). Finger millet for food and nutritional security. African Journal of Food Science, 6(4), 77-84, 29.

Sultana, F. (2014). Gendering climate change: Geographical insights. The Professional Geographer, 66(3), 372-381.

Suich, H., Howe, C., \& Mace, G. (2015). Ecosystem services and poverty alleviation: A review of the empirical links. Ecosystem Services, 12, 137-147.

Sustainable Agriculture Research and Education. (n.d.). Nonlegume cover crops. USDA. http://www.sare.org/Learning-Cent.

Synnott, P. (2012). Climate change, agriculture and food security in Nepal -Developing Adaptation Strategies and Cultivating Resilience.

Thornton, P. K. (2010). Livestock production: Recent trends, future prospects. Philosophical Transactions of the Royal Society B, 365, 2853-2867. https://doi.org/10.1098/rstb.2010.0134.

Tiwari, P. C., \& Joshi, B. (2016). Gender processes in rural out-migration and socio-economic development in the Himalaya. Migration and Development, 5(2), 330-350. https://doi.org/10. 1080/21632324.2015.1022970.
Tiwari, P. C., \& Joshi, B. (2012). Natural and socio-economic factors affecting food security in the Himalayas. Food Security, 4, 195-207. https://doi.org/10.1007/s12571-012-0178-z.

Townsend, P. (1979). Poverty in the United Kingdom: A survey of household resources and standards of living, 1967-1969. Harmondsworth: Penguin Books.

Trani, J. F., \& Bakshhi, P. (2013). Vulnerability and mental health in Afghanistan: Looking beyond war exposure. Transcultural Psychiatry, 50(1), 108-139.

Tulachan, P. M. (2001). Mountain agriculture in the Hindu Kush-Himalaya: A regional comparative analysis. Mountain Research and Development, 21(3), 260-267.

Turner, M. (2016). Climate vulnerability as a relational concept. Geoforum, 68, 29-38.

United Nations Development Programme (UNDP). (1990). Human development report 1990. New York: Oxford University Press.

UNDP. (1997). Human development report 1997. Human development to eradicate poverty. New York, NY: Oxford University Press.

UNDP. (1998). Human development report 1998. New York: Oxford University Press.

UNDP. (2010). The real wealth of nations: Pathways to human development. Human Development Report 2010. NewYork: UNDP.

UNDP. (2011). Integrated household living conditions assessment (IHLCA) survey in Myanmar. Yangon, Myanmar: United Nations Development Programme.

UNDP. (2015). Human development report. New York: UNDP. http:// hdr.undp.org/sites/default/files/2015_human_development_report. pdf.

Wang, J., Liu, Y. M., Cao, W., Yao, K. W., Liu, Z. Q., \& Guo, J. U. (2012). Anti-inflammation and antioxidant effect of Cordymin, a peptide purified from the medicinal mushroom Cordyceps sinensis in middle cerebral artery occlusion induced focal cerebral ischemia in rats. Metabolic Brain Disease, 27, 159-165.

Wagle, U. R. (2012). The food stamps program and economic security among low-income families part I. Poverty and Public Policy, 4(4), 223-238.

Wiltshire. (2014). Wiltshire uncovered report 2014. Wiltshire Community Foundation, Sandcliff House, 21 Northgate Street, Devizes, Wiltshire SN10 1JT.

Wangchuk, S., \& Siebert, S. F. (2013). Agricultural change in Bumthang, Bhutan: Market opportunities, government policies, and climate change. Society and Natural Resources: An International Journal. https://doi.org/10.1080/08941920.2013.789575.

World Bank. (2017). Poverty and equity data, world development indicators. Retrieved May 2017, from http://povertydata. worldbank.org/.

World Bank. (2009). India receives world's largest remittance flows. Washington, DC: Author. Retrieved 14 November, 2012, from http://worldbank.org/E6Y6IE0CQ0.

Woodrow, J., \& Anderson, M. (1989) Rising from the ashes: Development strategies in times of disaster. Community Development.

Wu, N., Yi, S., Joshi, S., \& Bisht, N. (eds) (2016). Yak on the move: Transboundary challenges and opportunities for Yak raising in a Changing Hindu Kush Himalayan Region. ICIMOD.

Yang, D., \& Choi, H. (2007). Are remittances insurance? Evidence from rainfall shocks in the Philippines. World Bank Economic Review, 21(2), 219-248.

Yi, S. L., Ning, W., Peng, L., Qian, W., Fusun, S., Geng, S., et al. (2007). Changes in livestock migration patterns in a Tibetan-style agropastoral system. Mountain Research and Development, 27(2), $138-145$. 
Yi, S. L., Ning, W., Peng, L., Qian, W., Fusun, S., Qiaoying, Z., \& Jianzhong M. (2008). Agricultural heritage in disintegration: Trends of agropastoral transhumance on the southeast Tibetan Plateau. International Journal of Sustainable Development \& World Ecology, 15(3).

Yi, S. L., \& Ismail, M. (2011). From pastoral economy to rangeland economy: capturing the multifunctionalities of rangeland resources.
In K. Kreutzmann, Y. Yang, \& J. Richter (Eds.), Pastoralism and rangeland management on the Tibet Plateau in the context of climate and global change. GIZ: Bonn.

Zimmerer, K. (2010). Biological diversity in agriculture and global change. Annual Review of Environment and Resources, 35, 137166.
Open Access This chapter is licensed under the terms of the Creative Commons Attribution 4.0 International License (http:// creativecommons.org/licenses/by/4.0/), which permits use, sharing, adaptation, distribution and reproduction in any medium or format, as long as you give appropriate credit to the original author(s) and the source, provide a link to the Creative Commons license and indicate if changes were made.
The images or other third party material in this chapter are included in the chapter's Creative Commons license, unless indicated otherwise in a credit line to the material. If material is not included in the chapter's Creative Commons license and your intended use is not permitted by statutory regulation or exceeds the permitted use, you will need to obtain permission directly from the copyright holder. 